NBER WORKING PAPER SERIES

\title{
ASSET ALLOCATION IN BANKRUPTCY
}

\author{
Shai Bernstein \\ Emanuele Colonnelli \\ Ben Iverson \\ Working Paper 23305 \\ http://www.nber.org/papers/w23305
NATIONAL BUREAU OF ECONOMIC RESEARCH
1050 Massachusetts Avenue
Cambridge, MA 02138
March 2017

The views expressed herein are those of the authors and do not necessarily reflect the views of the National Bureau of Economic Research.

NBER working papers are circulated for discussion and comment purposes. They have not been peer-reviewed or been subject to the review by the NBER Board of Directors that accompanies official NBER publications.

(C) 2017 by Shai Bernstein, Emanuele Colonnelli, and Ben Iverson. All rights reserved. Short sections of text, not to exceed two paragraphs, may be quoted without explicit permission provided that full credit, including $\odot$ notice, is given to the source. 
Asset Allocation in Bankruptcy

Shai Bernstein, Emanuele Colonnelli, and Ben Iverson

NBER Working Paper No. 23305

March 2017

JEL No. G3,G33

\section{ABSTRACT}

This paper investigates the consequences of liquidation and reorganization on the allocation and subsequent utilization of assets in bankruptcy. Using the random assignment of judges to bankruptcy cases as a natural experiment that forces some firms into liquidation, we find that the long-run utilization of assets of liquidated firms is lower relative to assets of reorganized firms. These effects are concentrated in thin markets with few potential users, and in areas with low access to finance. The results highlight the importance of local search frictions and financial frictions in affecting the allocation of assets in bankruptcy.

Shai Bernstein

Stanford Graduate School of Business

655 Knight Way

Stanford, CA 94305

and NBER

shaib@stanford.edu

Emanuele Colonnelli

Stanford University

Department of Economics

579 Serra Mall

Stanford, CA 94305

e.colonnelli@gmail.com
Ben Iverson

Northwestern University

2001 Sheridan Road

Evanston, IL 60208

b-iverson@kellogg.northwestern.edu 
Declining industries, insolvency and distressed firms are unavoidable consequences of an evolving economy. The ability of an economy to subsequently direct assets to better uses has important implications for productivity and the speed of recovery following adverse economic shocks (Eisfeldt and Rampini (2006); Hsieh and Klenow (2009); Bartelsman et al. (2013)). Since economies rely on courts to resolve insolvency, bankruptcy institutions play an important role in allocating the assets of distressed firms. Two approaches characterize bankruptcy institutions: liquidation and reorganization (Hart (2000); Strömberg (2000); Djankov et al. (2008)). While the liquidation procedure winds down the firm and puts all assets back on the market, reorganization aims at rehabilitating the company whenever possible.

Despite the importance of the bankruptcy system, empirical evidence on key questions is scarce: How do bankruptcy regimes affect asset allocation and utilization? Are assets in liquidation utilized similarly to assets in reorganization? If not, what frictions lead to different consequences of the two bankruptcy approaches?

Theoretically, with frictionless markets, the outcomes of both bankruptcy approaches should be similar, as both regimes should effectively allocate assets to their best use. This null hypothesis may no longer hold, however, when frictions are present. For example, conflicts of interests between claimholders, information asymmetry, and coordination costs in reorganization may lead to inefficient continuation affecting asset allocation (Baird (1986); Gertner and Scharfstein (1991); Aghion et al. (1992); Ivashina et al. (2015)). In liquidation, assets may not reallocate to best uses if they are specific to the firm, and markets are thin with few potential users (Williamson (1988); Gavazza (2011)). Misallocation may be further exacerbated if potential users of the assets are financially constrained (Shleifer and Vishny (1992)).

To answer these questions, it is necessary to tackle two important issues. First, there is little information on how assets are reallocated between firms and how assets are subsequently utilized, particularly in bankruptcy, when plants are shut down and firms are dissolved. Second, distressed firms that go through liquidation may be fundamentally different from firms that are reorganized. This is a common limitation to papers that explore the implications of different bankruptcy codes. Any comparison between two insolvent firms that experience different bankruptcy regimes may be biased due to unobserved differences in firm prospects and other characteristics.

In this paper we focus on the U.S. bankruptcy system and compare the consequences of liquidation (under Chapter 7 of the bankruptcy code) with reorganization (under Chapter 11 of the bankruptcy code) on asset allocation and utilization. To do so, we focus on the real estate assets used by bankrupt firms, and construct a novel dataset that tracks the allocation and utilization 
of these assets over time. Real estate assets represent a significant portion of firms' total capital. ${ }^{1}$ Moreover, these assets are likely to be highly specific, as the optimal user varies significantly with building features and location characteristics. For example, an industrial warehouse is unlikely to be suitable for a retail store, and a restaurant is unlikely to be replaced with a hotel. Further, locations benefit firms differently as they provide access to customers and suppliers, local labor markets, and knowledge spillovers (Ellison et al. (2010)).

We combine the U.S. Census Bureau's Longitudinal Business Database (LBD) with bankruptcy filings from LexisNexis Law, to obtain a dataset with rich information on 129,000 establishments belonging to 28,000 bankrupt firms employing close to 4.7 million workers at the time of bankruptcy. The comprehensive nature of these data allows us to examine the population of bankrupt firms in the U.S., including small and private businesses. An important methodological contribution of this work is the creation of geographic linkages that track occupier identities and economic activity at real estate assets over time. This allows us to capture the allocation and utilization of assets even when plants shut down and the real estate is vacant, or when it is used for a different purpose than the original plant. ${ }^{2}$

To explore long-run (five-year) allocation and utilization of these assets we rely on several measures. We explore the length of time a location continues to be operated by the bankrupt firm and, if it does not continue, whether it is occupied by a new firm or remains vacant. In addition to the occupancy rate, we explore the average number of employees at a given location over time. While the former measure captures only whether economic activity takes place in a given asset, the latter measure also captures the intensity of such economic activity.

Tracking assets in bankruptcy reveals several interesting stylized facts. First, both liquidation and reorganization lead to substantial asset reallocation. Second, when an asset is redeployed to a different user, it is most likely to a local firm and typically remains within the same industry, suggesting a significant degree of asset specificity and search costs, consistent with Williamson (1988) and Ramey and Shapiro (2001). Finally, we find that industry conditions and, especially, local economic activity are important determinants of asset reallocation and utilization, consistent with the importance of market liquidity and economic conditions for asset redeployment (Shleifer

\footnotetext{
${ }^{1}$ Based on Flow-of-Funds tables from the Federal Reserve, nonresidential structures (value of buildings, excluding the value of the land) accounted for $\$ 8.2$ trillion of real assets, while nonresidential equipment comprised only $\$ 4$ trillion at the end of 2014.

${ }^{2}$ These circumstances are not fully captured by the standard LBD linkages that link plants over time. For example, if an auto parts manufacturer, AutoABC, is shut down, and the building is then occupied by a shoes manufacturer, ShoesXYZ, linkages at the LBD will consider the death of AutoABC and the birth of ShoesXYZ as two separate incidents. Our linkages will connect the two, showing that ShoesXYZ replaced AutoABC in this real estate location. For details on how LBD linkages are constructed, see Jarmin and Miranda (2002). We describe our linkages in detail in Section IV.A and in the Appendix.
} 
and Vishny (1992); Gavazza (2011)).

In the main analysis, in order to deal with the endogeneity of the bankruptcy regime, we employ an instrumental variables strategy that exploits the fact that U.S. bankruptcy courts use a blind rotation system to assign cases to judges, effectively randomizing filers to judges within each court division. While there are uniform criteria by which a judge may convert a case from Chapter 11 to Chapter 7, there is a significant variation in the interpretation of these criteria across judges.

Our empirical strategy compares bankrupt firms that are reorganized within Chapter 11 to firms that file for Chapter 11 but are converted to Chapter 7 liquidation due to the assignment of the judge. In effect, otherwise identical filers are randomly placed in either reorganization or liquidation due to the random judge assignment, thereby allowing us to compare asset outcomes across the two regimes. Our empirical strategy follows a growing set of papers that takes advantage of the random assignment of judges and variations in judge interpretation of the law (Kling (2006); Doyle Jr (2007); Chang and Schoar (2013); Dobbie and Song (2015); Galasso and Schankerman (2015)).

This empirical strategy allows us to explore the following question: if a given firm had not been reorganized, how would its assets have been redeployed through liquidation ${ }^{3}$ We first show that, as expected, bankrupt plants in liquidation are more likely to be shut down, relative to reorganization, and they shut down more quickly. But interestingly, even after accounting for the subsequent reallocation of real estate to new users, liquidated plants are $17.4 \%$ less likely to be occupied five years after the bankruptcy filing, suggesting that in liquidation, on average, assets are less utilized. In addition, the average number of employees at liquidated locations is significantly lower relative to reorganized locations. These findings illustrate that bankruptcy regimes have large effects on long-run asset allocation and utilization.

To better understand which frictions lead to the gap in utilization between reorganization and liquidation, we explore the role of search frictions in limiting asset allocation. Search frictions can arise in thin markets with few potential users (Williamson (1988); Gavazza (2011)), and when potential asset users are financially constrained (Shleifer and Vishny (1992)). Empirically, we rely on two measures of search costs. First, we create a measure of market thickness which assesses the extent to which potential users of the bankrupt plant's real estate reside locally. Second, since assets typically reallocate to new and local businesses, we explore measures that identify markets with low access to small business finance.

We find that the drop in utilization is significantly larger in thin markets and areas with low

\footnotetext{
${ }^{3}$ We use the terms "reorganization" and "liquidation" to refer to bankruptcy procedures similar to Chapter 11 and Chapter 7, respectively. Importantly, this usage of the terms "reorganization" and "liquidation" is separate from the ultimate outcome of the bankruptcy. Firms in a reorganization bankruptcy regime can be liquidated if that is the outcome of the bargaining process. The key difference is that liquidation is forced under a cash auction system like Chapter 7, while it is not with structured bargaining.
} 
access to capital. Five years following the bankruptcy filing, plants in thick markets are equally likely to be occupied regardless of the bankruptcy regime, due to significant asset reallocation to new users in liquidation. In sharp contrast, liquidated plants in thin markets are over $30 \%$ less likely to be occupied than otherwise-identical assets in reorganized firms. Similarly, we find no long-term differences in employment across the two bankruptcy regimes in thick markets, but significantly lower employment when assets are liquidated in thin markets. We also find that local access to finance affects asset allocation in bankruptcy. In regions with high access to finance, we find similar levels of utilization for both liquidated and reorganized establishments. But in markets with low access to finance, liquidated assets are less likely to be occupied and have significantly lower employment relative to plants in reorganization. ${ }^{4}$

The results thus far highlight that search frictions and financial frictions can importantly affect the allocation of assets in bankruptcy. A natural next question is whether the results are driven by inefficient liquidation, in which high search frictions lead to under-utilization of the assets, or alternatively, if agency costs in the reorganization process lead to inefficient continuation of the firm and over-utilization of the assets. Clearly, answering this question is difficult because it depends on the unobserved opportunity cost of the real estate asset, and thus we do not fully rule out either possibility. ${ }^{5}$

While answering this question conclusively is challenging, several pieces of evidence are consistent with the interpretation that inefficient liquidation leads to under-utilization of assets in thin markets or markets with low access to finance. First, it is important to highlight that because of the random assignment, the opportunity cost of the asset is likely orthogonal to judge characteristics, and therefore our results compare assets with similar opportunity costs, and yet, liquidation leads to lower utilization, and therefore possible under-utilization. Second, we proxy for the unobserved opportunity cost by measuring the local vacancy rate of non-bankrupt assets, with the assumption that areas with low local vacancy rates have high demand for real estate assets and thus high opportunity costs of vacancy. We find that the effects of liquidation are similar in areas with high and low local vacancy rates. That is, liquidation leads to lower utilization when search costs are high, even if the opportunity cost of doing so is high.

In addition, we relate our empirical findings to a more formal theoretical framework by extending the dynamic search model of Gavazza (2011) to incorporate bankrupt firms that face either (a)

\footnotetext{
${ }^{4}$ The correlation between our measures of market thickness and access to finance is 0.10 , suggesting that each of these channels captures different search frictions that are responsible for the gap between liquidation and reallocation.

${ }^{5}$ It is particularly important to note that this paper only considers the efficiency of the asset allocation in each bankruptcy regime. There are, of course, many other aspects of bankruptcy, such as legal fees, creditor recoveries, and worker outcomes, that enter into the overall costs and benefits of liquidation and reorganization which we do not consider here.
} 
agency costs in reorganization, which may lead to inefficient continuation, or (b) forced sales in liquidation, which could be inefficient due to search frictions. Consistent with our empirical findings, the model predicts that liquidation leads to lower utilization in thin markets, relative to reorganized firms. However, this prediction only holds if agency costs in reorganization are low. When agency costs are high, relatively unproductive firms continue to hold real estate in reorganization and therefore one would expect that that liquidation will lead to higher utilization by allowing assets to reallocate to better users. Our empirical results do not match this prediction, as even in thick markets we do not find that liquidation results in higher utilization than reorganization. Therefore, our findings are consistent with the idea that when search frictions are high they may hinder asset allocation in liquidation, and inconsistent with the explanation that high agency costs in reorganization can explain the results.

This paper contributes to several strands of literature. It is most directly related to Maksimovic and Phillips (1998), who explore how industry conditions affect the reorganization of large manufacturing firms in Chapter 11. More broadly, this paper highlights the importance of local market characteristics in affecting the consequences of liquidation and reorganization on asset allocation, and thus contributes to an extensive body of theoretical and empirical literature that discusses the optimal design and frictions of the bankruptcy process. ${ }^{6}$ Second, a large literature explores the existence and implications of fire sales. ${ }^{7}$ This paper adds to this literature by relying on random variation that forces liquidation, which allows exploring subsequent reallocation and utilization of assets separately from reasons that initially lead to the forced sale. Finally, this paper also contributes to the literature that highlights the importance of labor and asset allocation for economic activity, by studying frictions that may impede reallocation. ${ }^{8}$

The remainder of the paper is organized as follows. Section I discusses the bankruptcy process. Section II provides a theoretical framework for our empircal results. Section III discusses the data construction. Section IV introduces the measurement of asset reallocation and Section V presents the empirical strategy. Section VI provides the main results in the paper. Section VII discusses the efficiency implications of our findings and Section VIII concludes.

\footnotetext{
${ }^{6}$ Some theoretical examples include Baird (1986, 1993); Gertner and Scharfstein (1991); Aghion et al. (1992); Shleifer and Vishny (1992); Hart (2000), and empirical studies include Hotchkiss (1995); Strömberg (2000); Davydenko and Franks (2008); Eckbo and Thorburn (2008); Benmelech and Bergman (2011); Chang and Schoar (2013) among others.

${ }^{7}$ For example, see Pulvino (1998, 1999); Ramey and Shapiro (2001); Campbell et al. (2011). Shleifer and Vishny (2011) surveys this literature.

${ }^{8}$ See, for example, Davis and Haltiwanger (1992); Eisfeldt and Rampini (2006); Hsieh and Klenow (2009); Ottonello (2014).
} 


\section{The Bankruptcy Process}

Bankruptcy procedures can be broadly classified into two main categories: liquidation through a cash auction, and reorganization through a structured bargaining process (Hart (2000)). The U.S. Bankruptcy code contains both procedures, with liquidation falling under Chapter 7 and reorganization taking place in Chapter 11 of the code. Bankruptcy formally begins with the filing of a petition for protection under one of the two chapters. In nearly all cases, it is the debtor that files the petition and chooses the chapter of bankruptcy, although under certain circumstances creditors can also file for an involuntary bankruptcy. Firms can file for bankruptcy where they are incorporated, where they are headquartered, or where they do the bulk of their business (see 28 USC $\S$ 1408), thereby giving the largest, nationwide firms some leeway in the choice of bankruptcy venue. However, once a firm files for bankruptcy, it is randomly assigned to one of the bankruptcy judges in the divisional office in which it files. This random assignment is a key part of our identification strategy, which we outline below.

Firms that file for Chapter 7 bankruptcy expect to liquidate all assets of the firm, and hence face a relatively straightforward process, although it can be lengthy (Bris et al. (2006)). A trustee is put in place to oversee the liquidation of the assets of the firm, and proceeds from the asset sales are used to pay back creditors according to their security and priority. According to U.S. Court filing statistics, liquidations are frequent, as about $65 \%$ of all business bankruptcy filings in the U.S. are Chapter 7 filings.

A significant portion of firms that originally file for Chapter 11 bankruptcy also end up in Chapter 7 through case conversion. Conversion to Chapter 7 occurs when the bankruptcy judge approves a petition to convert the case. Conversion petitions are typically filed either by a creditor or the court itself (e.g. by a trustee), accompanied with a brief which outlines why liquidation will provide the highest recovery for the creditors. As we discuss in Section V, the judge plays an important role in the decision to convert the case to Chapter $7 .{ }^{9}$ However, once a case has been converted, the responsibility to liquidate the estate is passed to a trustee, and thus the judge plays little role in the reallocation of assets for these cases from that point forward. Meanwhile, firms that remain in Chapter 11 proceed with the reorganization through a structured bargaining process governed by specific rights and voting rules defined by the law. ${ }^{10}$

\footnotetext{
${ }^{9}$ We examined court documents for a random sample of 200 cases and found that, on average, a motion to convert a case occurs 4 months after the bankruptcy filing. Importantly, in nearly all cases this is the first major motion on which a judge rules.

${ }^{10}$ Specifically, the debtor firm creates a plan of reorganization which outlines which assets will be retained or sold, how the firm will be restructured, and what recoveries creditors will receive. This plan is then distributed to creditors who vote on the plan. The plan is approved if $2 / 3$ of creditors accept the plan. Because plans are typically negotiated with creditors prior to the vote, plan rejections are rare.
} 
Importantly, Chapter 11 allows for some or all of the assets of the firm to be liquidated should that be the outcome of the bargaining process. The key difference from Chapter 7 is that it is not forced. Assets that are owned by the firm can be sold via "Section 363 sales," in which some or all of the firm's assets are auctioned off while the firm remains in bankruptcy. ${ }^{11}$ Similarly, in Chapter 11 there is negotiation that determines whether assets that are leased (as much commercial real estate is) should be retained or returned to their owners. Firms in Chapter 11 have the ability to choose which leases to accept and which to reject, thereby terminating the contract. In Chapter 7 , leases are automatically rejected, thereby forcing the lessor to find a new tenant. Thus, regardless of whether an asset is owned or leased, Chapter 11 allows for negotiation surrounding which assets are kept in the firm, while a new buyer or user must be found for assets in Chapter $7 .{ }^{12}$

In this paper, we compare asset allocation and utilization across these two bankruptcy procedures. The key difference between the procedures for our purposes is that in Chapter 7 liquidation all assets are potentially reallocated, while in Chapter 11 reorganization there is negotiation over which assets remain with the bankrupt firm, or whether that firm survives at all.

\section{Theoretical Framework}

In this section we provide a theoretical framework to analyze asset allocation between firms. To do so, we briefly outline an extension to the search model of Gavazza (2011) that models the dynamics of buyer and seller firms that face search frictions and explores the role of market thickness. Our extension incorporates two types of bankrupt sellers: (a) reorganized sellers that face agency costs or (b) liquidated sellers that are forced to sell after the firm shuts down. In section II.A below we briefly describe the basic setting of Gavazza (2011), and in section II.B we describe our extension and introduce bankrupt firms. This framework guides the empirical analysis, and aids in understanding the efficiency implications of our findings, as discussed in Section VII. In this section we provide the intuition of the model, leaving the formal derivations to Appendix B.

\section{A. Basic Setup}

The setup is built on a decentralized market with two-sided search by buyer and seller firms (Mortensen and Wright (2002); Gavazza (2011)). Firm production relies on a single asset, and firms are differentiated by heterogeneous productivity that evolves exogenously over time. If firms own an asset, they choose its level of utilization to maximize the per-period profits from its use, with

\footnotetext{
${ }^{11}$ Alternatively, some or all of the assets of the firm can be liquidated through a formal plan of reorganization. Creditors are allowed to vote on these plans.

${ }^{12} \mathrm{~A}$ full discussion of the treatment of leases in Chapter 11 can be found in Ayotte (2015).
} 
more productive firms choosing a higher level of utilization. ${ }^{13}$ Firms endogenously select whether to enter the market and become active buyers or sellers based on their productivity. When a firm enters the market (either to buy or sell), it pays a search cost to contact other firms willing to trade, and buyers and sellers meet according to a Poisson process. Once two firms meet and are willing to trade, they negotiate a trading price.

As illustrated by Gavazza (2011), there exist unique productivity cutoffs for buyers and sellers that determine their entry into the market. A firm that does not currently own an asset will enter the market if its productivity increases above the buyers' cutoff. Similarly, a firm that currently owns an asset will choose to sell it if its productivity falls below the sellers' cutoff. The buyers' threshold is higher than the sellers' cutoff, and the larger the wedge between these two cutoff values the slower the reallocation of assets towards more productive users.

Market thickness, defined as the number of potential buyers and sellers in the market, is an important driver of the wedge between the two cutoffs. The key economic force is that, in a thicker market, the contact rate between buyers and sellers is higher, assets that are on the market trade faster, and therefore search costs are lower. Therefore, in thin markets firms choose to hold onto assets for longer periods, in case their productivity rises in the future, since it is more difficult and costly to find a buyer. Similarly, potential buyers are less likely to actively search for a seller. As a result, only very productive firms choose to become buyers and very non-productive firms choose to become sellers in thin markets, so that the wedge between cutoff values is larger. As the asset market becomes thicker, the sellers' cutoff value increases and the buyers' cutoff value decreases.

Panel (a) of Figure 1 provides a numerical illustration of the equilibrium behavior of buyers and sellers, showing how the buyers and sellers cutoffs change as market thickness increases. ${ }^{14}$ Sellers with a productivity realization below the black dashed line are willing to sell the assets to interested buyers with productivity levels above the black solid line. Panel (b) of Figure 1 illustrates that the average holding time - the length of time the current owner holds the asset - declines with market thickness as expected (see black dotted line), since the probability of a buyer-seller meeting is higher. Since assets reallocate faster to more productive users in thicker markets, the average productivity of asset users is higher and so asset utilization is also higher, as shown by the black dotted lines in Panels (c) and (d).

While the model focuses on market thickness, the same intuition applies in the presence of financing constraints as in Shleifer and Vishny (1992). When potential buyers are financially con-

\footnotetext{
${ }^{13}$ More productive firms will choose a higher level of utilization because they can produce more at lower cost, thereby increasing their optimal utilization level. As pointed out by Gavazza (2011), this is true as long as productivity and utilization are complements in the production function.

${ }^{14}$ This numerical illustration follows Gavazza (2011), see the Appendix for more details.
} 
strained they are less likely to become active buyers, sellers face essentially thinner asset markets and higher search costs and are therefore inclined to hold on to the assets for longer periods.

\section{B. Introducing Bankrupt Sellers}

We introduce two types of bankrupt sellers in the model: liquidated sellers and reorganized sellers. We assume for simplicity that the number of bankrupt sellers is small and thus they do not affect the equilibrium behavior of regular buyers and sellers in the economy. Their objective functions, however, differ from regular sellers in important ways.

In liquidation, the firm ceases to exist, and sellers can no longer use the asset to generate intermediate profits. This makes liquidated sellers particularly eager to sell the asset relative to regular sellers. Since liquidated sellers are likely to become active sellers in almost any level of market thickness, they are particularly exposed to market conditions. When markets are thin, search times are lengthy, during which liquidated sellers do not utilize the asset.

Meanwhile, in reorganization the firm continues to operate and can still generate intermediate profits from the asset, thereby avoiding impatient sales and unused assets. However, because of agency problems, managers may continue to hold on to the assets, despite the availability of more productive potential buyers, because the cost of doing so is mostly borne by senior claimants (Baird (1986); Jensen and Meckling (1976)). ${ }^{15}$ We model agency costs as private benefits that managers receive from continuing the firm and holding on to the asset. The implications of this assumption can be illustrated in Panel (a) of Figure 1. Reorganized sellers' cutoff for becoming active sellers (red dashed line) is lower than regular sellers, and therefore they are willing to become active sellers only if they experience a particularly bad productivity shock. Therefore, they hold on to the assets inefficiently, relative to regular sellers, and may pass up opportunities to reallocate the asset to more productive users. $^{16}$

The differences between liquidated and reorganized sellers can be illustrated through the average asset holding time. As shown in Panel (b) of Figure 1, the asset holding time of liquidated sellers is much shorter than regular sellers, while reorganized sellers hold the asset longer than regular

\footnotetext{
${ }^{15} \mathrm{He}$ and Matvos (2015), for example, provide a model where debt exists to limit excessive continuation by causing financial distress. However, many question if bankruptcy actually limits inefficient continuation. Chapter 11 allows current managers to retain control of the firm and gives them the exclusive right to propose a plan of reorganization. In addition, voting rules can allow junior claimants or management to push for continuation even when their claims are out of the money, which they might do to preserve their jobs or to gain some recovery value (Bradley and Rosenzweig (1992), Hart (2000)). Thus, financial distress creates a larger wedge between ownership and control, while bankruptcy laws serve to actually strengthen the control of current managers and equity holders in the reorganization regime. Other papers that provide theoretical arguments for excessive continuation based on agency costs include Gertner and Scharfstein (1991) and Bebchuk and Chang (1992).

${ }^{16}$ For liquidated sellers, markets need to be extremely thin to deter them from actively searching for a buyer, and therefore their threshold is not presented in Panel (a) of Figure 1.
} 
sellers. This is because liquidated sellers almost always actively search for a potential buyer and therefore sell the asset much more quickly. In contrast, reorganized sellers, due to the agency cost, are less likely to actively seek a buyer, and therefore hold the asset longer. Interestingly, the gap in holding time between liquidated and reorganized sellers narrows as the market becomes thicker, as reorganized sellers become more willing to sell when search frictions decline. This motivates our first hypothesis:

Hypothesis \#1: Asset holding time is shorter in liquidation than in reorganization. However, the gap declines as market thickness increases.

We use the model to calculate asset utilization over the lifetime of an asset. For liquidated sellers, the assets are not used until they are sold, while reorganized sellers can utilize the asset until they decide to sell. The long-run utilization, therefore, depends on the holding time, and also on the productivity of the buyer after reallocation takes place. Panel (c) plots the average asset utilization for regular sellers (black dotted line), liquidated sellers (blue line) and reorganized sellers (red dashed line). In thin markets, liquidation leads to lower utilization than reorganization. However, as markets become thicker, utilization in liquidation grows faster than in reorganization, such that there is a crossing point at which asset utilization in liquidation becomes greater than in reorganization. This is because liquidated sellers can reallocate the asset more quickly to more productive buyers when markets are thick. ${ }^{17}$ In contrast, reorganized sellers are slower to sell and more insulated from the markets due to the private benefits from holding the asset and the ability to generate intermediate profits.

The model gives similar predictions with respect to the average life-long productivity of the asset users, as illustrated in Panel (d). In thin markets, the average productivity of users is higher in reorganization because it is difficult for liquidated sellers to find a buyer. However, as markets become thicker, the average productivity of assets in liquidation increases sharply and the gap between reorganization and liquidation productivity narrows until it becomes higher in liquidation. ${ }^{18}$ This leads to a second testable hypothesis:

Hypothesis \#2: Asset utilization and productivity increase with market thickness for both

\footnotetext{
${ }^{17}$ As markets get thicker, the holding time of liquidated sellers decline because more potential buyers are becoming active. This is hard to see in Panel (b) of Figure 1 since the holding time of reorganized sellers is much larger and we rely on the same scale. However, in the numerical illustration, the holding time of liquidated sellers drops from 1.3 in thin markets to 0.3 in thick markets. That is, a four fold decline in the holding time of the asset.

${ }^{18} \mathrm{It}$ is important to note that these predictions are based on a model with only low agency costs. If agency costs are high, then utilization and productivity of reorganized assets is always lower than that of liquidated assets, even in thin markets, and the gap increases with market thickness. The empirical findings are inconsistent with the predictions of high agency costs scenario, as we discuss this in detail in Section VII below.
} 
reorganized and liquidated sellers. However, since liquidated sellers are more sensitive to changes in market thickness, the increase is faster in liquidation than in reorganization.

This hypothesis implies that if utilization and producitivity are higher in reorganization in thin markets, relative to liquidation, this gap should decline or dissapear as markets become thicker.

As mentioned above, to ease the exposition we have described the implications of the model with regards to market thickness. However, similar results hold if one varies the accessibility of capital, as in Shleifer and Vishny (1992), since financing constraints will limit the set of potential buyers, and sellers will face thinner markets with higher search costs. Accordingly, in Section VI.B we test empirically how the gap between liquidation and reorganization changes both with respect to market thickness and access to capital.

Importantly, this theoretical framework also helps to interpret the relative importance of agency costs and search frictions that face bankrupt sellers. Specifically, when agency costs are high relative to search costs, the utilization and productivity of reorganized sellers can be reduced to levels below those of liquidated sellers since reorganized sellers will resist reallocating the assets. Thus, comparing the utilization of assets in liquidation and reorganization across levels of market thickness can help us understand which frictions affect asset allocation in bankruptcy. We discuss this issue in detail in Section VII below.

\section{Data}

\section{A. Bankruptcy Filings}

We gather data on Chapter 11 bankruptcy filings from LexisNexis Law, which obtains filing data from the U.S. Courts system. This data contains legal information about each filing, including the date the case was filed, the court in which it was filed, the judge assigned to the case, an indicator of whether the filing was involuntary or not, and status updates on the case. From the status updates, we are able to identify cases that were converted to Chapter 7 . The LexisNexis dataset contains a few bankruptcies beginning as early as 1980, but coverage is not complete in these early years as courts were still transitioning to an electronic records system. We begin our sample in 1992, when LexisNexis' coverage jumped to over 2,000 bankruptcy filings per year (from 450 in 1991) across 70 different bankruptcy districts (out of 91). By 1995, LexisNexis covers essentially 100\% of all court cases across all bankruptcy districts. ${ }^{19}$ The comprehensive nature of the LexisNexis data makes this one of the largest empirical studies on bankruptcy to date, including both public and private firms

\footnotetext{
${ }^{19}$ Iverson (2015) provides more details of the LexisNexis data.
} 
from all bankruptcy districts and across all industries. We end our sample with cases that were filed in 2005 so as to be able to track bankrupt firms for a five-year period after the bankruptcy filing.

\section{B. Census Data and Measures of Local Market Characteristics}

We match bankruptcy filings from LexisNexis to their establishments in the U.S. Census Bureau's Business Register (BR), which we then link to the Longitudinal Business Database (LBD). The LBD includes all non-farm tax-paying establishments in the U.S that employ at least a single worker. In the LBD, an establishment is a physical location where economic activity occurs. This serves as the main unit of observation in our study.

We match the bankruptcy filings from LexisNexis to the BR using the employer identification number (EIN), which is contained in both datasets. Importantly, each legal entity of a firm can have a separate EIN, and thus there can be multiple EINs (and multiple bankruptcy filings) for each firm. Further, an EIN can have multiple establishments connected to it in the LBD. We match bankrupt EINs to all establishments in the BR in the year of the bankruptcy filing to form our initial sample of bankrupt plants. This sample is then reduced due to missing addresses (which are necessary to track economic activity at a location), resulting in a final sample of 129,000 establishments belonging to 28,000 unique firms. ${ }^{20}$

Table 1 presents summary statistics for our final sample. Panel A shows that the average firm in our sample has 4.7 establishments and employs 169 individuals. In total, firms employ 4.7 million individuals at the time of the bankruptcy filing. Approximately $40 \%$ of the bankruptcy filings in our sample convert to Chapter 7 liquidation. Further, there are stark differences between firms that stay in Chapter 11 and those that are converted to Chapter 7. The average Chapter 11 firm has nearly three times as many establishments and over four times as many employees. ${ }^{21}$ These differences are apparent also at the level of the plant, where plants of Chapter 11 firms employ almost $50 \%$ more workers than those of firms that convert to Chapter 7. In addition, Chapter 11 firms have higher payroll per employee ( $\$ 26,000$ per year versus $\$ 20,200$ at Chapter 7 firms) and are about two years older than Chapter 7 firms. The differences between Chapter 11 and Chapter 7 firms highlight the importance of selection into bankruptcy regimes, and hence the need for identification in assessing the impact of the regimes.

Panel B of Table 1 shows the industry distribution of plants and firms in our sample. Firms are distributed across all industries, with wholesale and retail trade and services making up the largest

\footnotetext{
${ }^{20}$ We provide extensive details of the matching process and sample selection in Appendix C.

${ }^{21}$ Census disclosure rules prohibit reporting medians or percentiles, but Table 4 reports the number of firms in different size categories to give a better representation of the size distribution of our sample.
} 
portions of the sample. ${ }^{22}$ We do not see large differences in the share of firms that are liquidated across different sectors; roughly $40 \%$ of firms are converted to Chapter 7 in all industries.

In Section VI.B, we explore two measures of heterogeneity of local market characteristics that are related to search frictions: market thickness and access to capital. Following Gavazza (2011), we first focus on market thickness as a principal driver of the ability to redeploy assets. Given that reallocation is typically done locally and within the same industry (as we show below), we expect that counties which contain many firms in the same or similar industries as the bankrupt plant will have lower search costs and hence a higher probability of finding a user of the vacated real estate. We use the full LBD to measure market thickness for industry $i$ in county $c$ in year $t$ as

$$
\text { Thickness } s_{i c t}=\sum_{j} \tau_{i j} s_{j c t}
$$

where $\tau_{i j}$ is the observed probability across our full sample that a plant in industry $i$ transitions to industry $j$ after closure, and $s_{j c t}$ is industry $j$ 's share of total employment in county $c$ in year $t{ }^{23}$ Thickness $s_{i c t}$ is essentially a weighted index of market concentration, where each industry is weighted by $\tau_{i j}$. $\tau_{i i}$, the probability that a plant remains in the same industry, is substantially higher than any other $\tau_{i j}$ for all industries, implying that it is often difficult to transition an asset to a new industry. Indeed, by weighting by $\tau_{i j}$, this measure of thickness accounts at least in part for two types of asset specificity. First, for some industries the physical characteristics of the asset are not suited for other uses, such as in the case of a factory, making reallocation difficult. Second, it can be that specific locations are better suited for particular businesses due to their proximity to suppliers or customers, as in the case of tech firms in Silicon Valley or retail stores in shopping malls. Thicknessict is highest when a given county has a high concentration of plants in the same or related industries, where there are many potential buyers who can use the asset for its intended purpose without having to overcome either form of asset specificity. Indeed, the same county can have both a high thickness measure for one type of asset and a low thickness measure for another, depending on the local industrial composition. Interestingly, in Appendix Table A.9 we show that market thickness is quite similar across industries, suggesting that the variation in this measure stems from geographic variation within industry, rather than across industries. In Panel A of Table 1, we also show that levels of market thickness are similar for both reorganized and liquidated firms.

Second, we focus on access to finance as a determinant of asset reallocation, as in Shleifer and Vishny (1992). Because the majority of new occupants of bankrupt assets are local or new

\footnotetext{
${ }^{22}$ The number of firms in Panel B sums to more than 28,000 because some firms have plants in different industries.

${ }^{23}$ Results remain unchanged if we define $s_{j c t}$ as the share of plants in industry $j$ rather than the share of employment.
} 
firms (as we discuss below), we expect that small business loans will be the principal source of capital for these firms (Petersen and Rajan (1994)). Accordingly, we use the share of loans going to small businesses in a county as a proxy for access to finance. We measure this share using the Community Reinvestment Act (CRA) disclosure data from the Federal Financial Institutions Examination Council (FFIEC), which contains data on loan originations by commercial banks for loans under $\$ 1$ million. ${ }^{24}$ Specifically, we proxy for access to capital by measuring the share of small business loan originations going to small businesses, defined as firms with less than $\$ 1$ million in annual gross revenue. ${ }^{25}$ In Panel $\mathrm{A}$ we find that the share of small business loans in regions of reorganized firms is similar to those in regions of firms that were converted to liquidation.

\section{Asset Allocation Measurement}

\section{A. Tracking Real Estate Assets Over Time}

In this section we describe the construction of geographical linkages that track bankrupt firms' real estate locations over time. We track assets even when plants are sold or shut down, thereby capturing whether real estate is occupied (by either a bankrupt firm or a different occupier), and if so, how intensively it is utilized, as captured by the asset's total employment. To do so, we rely on the Census LBD, which covers all non-farm, private sector establishments in the United States. A significant benefit of the LBD is that it captures the location of tax-paying establishments, thereby reporting the users of real estate assets. This allows us to carefully explore asset reallocation through the evolution of asset occupiers, and asset usage, regardless of whether the property is owned or leased. ${ }^{26}$

To track real estate occupancy and employment outcomes over time, we create a careful address matching algorithm to link addresses over time. First, we clean all addresses and address abbreviations using the United States Postal Service formal algorithm. ${ }^{27}$ Then, for each shut-down plant, we

\footnotetext{
${ }^{24}$ The CRA requires banks above a certain asset threshold to report small business lending each year. During our sample period, the asset threshold was $\$ 250$ million. Greenstone et al. (2014) estimate that CRA eligible banks accounted for approximately $86 \%$ of all loans under $\$ 1$ million.

${ }^{25}$ Following Greenstone et al. (2014), we define small business loans as those up to $\$ 1$ million, and small businesses as firms with less than $\$ 1$ million in annual gross revenue. Ideally, we would measure the share of all lending that goes to small firms, rather than just the share of loans under $\$ 1$ million, but county-level data on all loans is not available. Given that over $50 \%$ of loans less than $\$ 1$ million go to large firms, it is likely that nearly all loans greater than $\$ 1$ million go to large firms, and thus the share of CRA loans going to small businesses is a reasonable proxy for the share of all lending going to small businesses.

${ }^{26}$ An alternative approach would be to rely on real estate transactions, following changes in asset ownership. However, such an approach cannot identify whether assets are directed to different uses if reallocation occurs through leases. Moreover, this approach cannot identify when assets are vacant, and the extent to which the assets are used.

${ }^{27}$ See the following link (valid as of October 2016) for details of the postal addressing standards used: http://pe.usps.gov/text/pub28/
} 
attempt to match its address with subsequent LBD years (up to five years following the bankruptcy filing), to track the next occupier of the real estate location. ${ }^{28}$ We also match to previous years of the LBD up to three years prior to the bankruptcy to verify that the pre-trend in employment is unrelated to the judge instrument, as discussed in Section V. Our address matching algorithm forces a perfect match on both zipcode and street numbers for each location, and then allows for (almost perfect) fuzzy matching on street name and city name. The details of the address matching algorithm are provided in Appendix D.

With these geographical linkages, we categorize each plant outcome in the following manner. First, if a plant continues to operate (i.e. has positive payroll) after the bankruptcy filing under its original ownership we classify the plant as "continued." Second, if a real estate location is occupied and active, and is used by a different firm from the original bankrupt occupier, we classify it as "reallocated." 29 Such reallocation may not necessarily take place immediately. Therefore, in a given year, we say that a plant is "vacant" if the original plant has previously shut down and no active plant is currently occupying the real estate location.

We also link addresses of non-bankrupt plants in the same county as the bankrupt plants to create a benchmark of plant occupancy and utilization. To do so, we create a $5 \%$ random sample of all plants in the LBD in the same county and year as each bankrupt plant and track the asset allocation and utilization of this set of over 4 million establishments in exactly the same manner as the bankrupt establishments. ${ }^{30}$ This not only provides a benchmark against which to compare our results, but also provides an estimate of local area vacancy rates which can proxy for the opportunity costs of vacancy, as discussed in detail in Section VII below. ${ }^{31}$

\footnotetext{
${ }^{28}$ The LBD includes plant identifiers that link establishments over time. These plant linkages broadly rely on name and address matching (see Jarmin and Miranda (2002) for a detailed description of the construction of the plant linkages). Hence, plant linkages are maintained as long as a plant remains active under existing ownership or is sold and the new owner keeps the same plant name and address. Otherwise, the plant identifier link is not maintained. Our goal is to construct location-based linkages which are robust to any change in name, and follow plant locations more broadly. Importantly, in our sample the standard LBD linkages account for only about $25 \%$ of reallocation, while the geographical linkages we construct account for the remaining $75 \%$.

${ }^{29} \mathrm{~A}$ real estate location could be sold back to its original owner under a new legal entity, in which case it would be marked as "reallocated" in our data even though it has not truly been reallocated, as we lack the ability to determine if the new legal entity is related to the original owner. Strömberg (2000) shows that these "sale-backs" are relatively common in Sweden. However, in examining 100 randomly-selected bankruptcy cases in our sample we did not find any instances of asset sale-backs in the U.S.

${ }^{30}$ We also construct local benchmarks based on the same 3-digit NAICS and county as the bankrupt plant. In unreported results we find essentially identical figures.

${ }^{31}$ Because address matching is inherently imperfect, we conduct a variety of checks, including manually examining matches and comparing to external data, to ensure that our match quality is high and that our results are not dependent on matching issues. These checks are discussed in Appendix Section D.D. Further, Appendix Table A.8 shows that our results are robust to excluding plants for which matching is less precise, such as office buildings or shopping malls with many establishments.
} 


\section{B. Stylized Facts about Asset Allocation in Bankruptcy}

In this paper we construct measures of asset allocation and utilization of real estate assets. Given the novelty of the measures, in this section we describe three stylized facts that guide our main analysis in Section VI below.

\section{Stylized Fact 1: Asset Reallocation is Prevalent in Both Bankruptcy Regimes}

In Panel A of Figure 3, we explore whether plants continue to be operated by their initial users following the bankruptcy filing under either liquidation or reorganization. We find that when a bankruptcy filing is converted to Chapter 7 , only $54 \%$ of plants continue to operate under original ownership after one year, and only $8 \%$ by year three. While it is expected that liquidated plants will not continue, non-continuation is also prevalent in reorganization. Specifically, $70 \%$ of Chapter 11 plants continue after one year, and that figure drops to $39 \%$ by year three and $26 \%$ by year five. In comparison, non-bankrupt benchmark plants that are located in the same county have a survival rate of $71 \%$ after three years, and $59 \%$ by year five.

Panel B of Figure 3 provides evidence on the importance of reallocation in bankruptcy. The figure shows the probability that a location is occupied by any firm across the two bankruptcy regimes. A comparison of this panel with the figures in Panel A illustrates the extent to which assets are reallocated. Five years after bankruptcy, only $26 \%$ of reorganized plants continue with the original bankrupt firm, but $69 \%$ are occupied, meaning that $43 \%$ of these locations are reallocated to new users. Meanwhile, occupancy rates among liquidated plants are $55 \%$ by year five, and the occupancy of these plants is entirely due to reallocation. ${ }^{32}$ However, the occupancy rates of both bankruptcy regimes remain below that of the non-bankrupt benchmark for all years. A similar picture arises when exploring utilization in terms of total employment, as illustrated in Panel C of Figure 3. After accounting for reallocation to new users, employment at reorganized firms drops to about $70 \%$ of its pre-bankruptcy level by year three and remains close to that level. Meanwhile, employment drops quickly at liquidated plants and then recovers to just over $60 \%$ of pre-bankruptcy employment by year five after bankruptcy. These are strikingly different to employment at benchmark plants, whose employment grows slightly over time. ${ }^{33}$ Of the 3.25 million workers employed at bankrupt locations

\footnotetext{
${ }^{32}$ Even after accounting for reallocation, vacancy rates are still over $30 \%$ in year 5 among bankrupt firms, and $20 \%$ among the local benchmark of non-bankrupt firms. For reference, statistics collected by the National Association of Realtors indicate that commercial real estate vacancy rates nationwide average over $10 \%$, with levels as high as $20 \%$ not being uncommon (see http://www.realtor.org/reports/commercial-real-estate-outlook, link valid as of January 2016). Bankrupt firms are more likely to reside in poorly performing regions, and assets may be more likely to be neglected, thus explaining the higher vacancy rates. In a series of papers, Steven Grenadier (Grenadier (1995, 1996)) finds evidence for vacancy rates as high as 30\% in the Denver and Houston areas in the 1980s, and shows that the level of equilibrium vacancy rates is predominately determined by local factors. Moreover, he illustrates a significant persistence in vacancy rates in commercial real estate.

${ }^{33}$ The occupancy rate of benchmark plants naturally falls over time since by definition all benchmark plants are occupied in year 0 . However, overall employment increases at benchmark plants as non-vacant establishments grow
} 
by year 5, more than 2 million workers are employed at locations that have been reallocated to new users. Thus, by occupancy or employment, asset reallocation plays an important role in the utilization of these bankrupt assets. ${ }^{34}$

\section{Stylized Fact 2: Search Costs and Asset Specificity Matter for Reallocation}

We find that search costs and asset specificity are important features of the reallocation process in bankruptcy. In Panel $\mathrm{C}$ of Table 1 we explore the characteristics of reallocated bankrupt plants. We find that most assets are reallocated to local firms, either newly created businesses $(52.0 \%)$ or existing firms that already have at least a single plant in the same county (34.4\%). Non-local entrants account for only a small fraction $(13.6 \%)$ of total reallocations. This is especially true for liquidated plants, where new entrants account for $70.4 \%$ of all reallocation, and non-local entrants only make up $7.4 \%$. We also find a high degree of reallocation within industries, as the probability that reallocated asset will remain within the same 3-digit industry NAICS is $46.4 \%$. Note that if assets were to randomly transition between industries, the probability of reallocating within the same 3-digit industry would be about $2.2 \%$, given the size distribution of industries in the LBD. Interestingly, Panel $\mathrm{C}$ also shows that liquidated plants are about 11 percentage points less likely to remain in the same 3-digit NAICS than reorganized plants. These results are consistent with the literature documenting the importance of asset specificity and search cost in asset reallocation (Ramey and Shapiro (2001); Eisfeldt and Rampini (2006); Gavazza (2011)), as discussed above.

\section{Stylized Fact 3: Industry and Local Economic Conditions Affect Reallocation}

Finally, we find that industry and local economic conditions are important in determining the degree of asset reallocation. Table 2 reports regression results in which we limit the sample to plants that do not continue with the bankrupt firm, and explore what affects the probability that real estate assets will be reallocated and utilized by a new owner as opposed to remaining vacant. The dependent variable is an indicator equal to one if a new establishment occupies the real estate location within five years of the bankruptcy filing, and zero if the plant was closed but not replaced.

In column 1, we find that county-level characteristics are significant predictors of asset reallocation. In particular, we find that being located in a county with a high total number of plants, high economic growth (measured by three-year employment growth in a county), and high payroll per employee, are significantly correlated with a higher probability that a discontinued plant will be reallocated.

We find that industry-level conditions matter as well in column 2, which illustrates that real

by more than the drop in employment at vacant locations.

${ }^{34}$ Relatedly, we find that reallocation, when it takes place, occurs almost immediately in both bankruptcy regimes. Conditional on transitioning to a new user, approximately $65 \%$ of plants are reallocated in the same year they are shut down. The probability that the real estate is redeployed falls drastically in subsequent years. 
estate in high-growth industries is more likely to be reallocated. In column 3, we also report industry dummies to illustrate heterogeneity across industries in reallocation likelihood. For example, real estate in accommodation, food and entertainment, is much more likely to be reallocated (conditional on plant closure) relative to the mining and construction omitted category. This evidence suggests that the degree of asset specificity, and the number of potential buyers for commercial real estate may vary across industries.

In columns 4, 5, and 6 of Table 2, we control simultaneously for county-level and industry characteristics, and we vary the set of fixed effects that we include in the estimation. All county-level characteristics remain highly significant in these regressions as well as industry fixed effects, but the effect of industry growth rates falls to zero. Overall, the results highlight the cross-industry variations in reallocation propensities, and the importance of local economic conditions. This motivates our focus on local market conditions, and in particular the presence of local firms in similar industries, as important determinants of reallocation in bankruptcy. ${ }^{35}$

\section{Identification Strategy}

\section{A. Empirical Design}

Identifying the effect of Chapter 7 liquidation on asset allocation relative to Chapter 11 reorganization is challenging given the inherent selection into bankruptcy regimes. Firms filing directly for Chapter 7 may have worse prospects, and this will be reflected in the way their assets are allocated and subsequently utilized. To mitigate the selection, we focus only on firms that filed for Chapter 11 reorganization, and exploit the fact that a significant fraction (40\%) of these firms are converted to Chapter 7 liquidation subsequently. Hence, the baseline specification of interest is:

$$
Y_{p, i, t+k}=\alpha+\beta \cdot \text { Liquidation }_{p, i, t}+\gamma X_{p, i, t}+\epsilon_{p, i, t+k}
$$

where $p$ indexes an individual plant real estate used by firm $i, t$ is the year of the bankruptcy filing, and $k$ indexes the number of years after bankruptcy (ranging from one to five). The dependent variable $Y_{p, i, t+k}$ is a measure of post-bankruptcy plant outcomes and real estate asset utilization such as the total number of workers employed at real estate $p$ in year $t+k$. We are interested in estimating $\beta$, which captures the impact of conversion to liquidation on $Y_{p, i, t+k}$, after controlling for a set of firm- and plant-level variables, $X_{\text {pit }}$, such as pre-bankruptcy filing employment and plant age. We index Liquidation $_{p, i, t}$ as occurring in year $t$, since the decision of whether the case

\footnotetext{
${ }^{35}$ The fact that reallocation is strongly related to local market and industry conditions also supports the validity of our address-matching procedure. If the matching were noisy, such strong patterns would not emerge in the data.
} 
is converted to Chapter 7 liquidation or remains in Chapter 11 reorganization is typically taken in the bankruptcy filing year. ${ }^{36}$ Under the null hypothesis that liquidation has a similar effect on asset utilization as reorganization, $\beta$ should not be statistically different from zero.

Even within Chapter 11 filers there may be a significant amount of selection among firms that convert to Chapter 7 liquidation. Table 1 illustrates this point, as firms converted into Chapter 7 liquidation tend to have a smaller number of plants, employ fewer workers, and are slightly younger. Therefore, to identify the causal effect of liquidation on plant outcomes and asset allocation, we rely on judge heterogeneity in their propensity to convert Chapter 11 filings to Chapter 7 as an instrumental variable. ${ }^{37}$ This instrument does not rely on differences in actual bankruptcy laws, as the bankruptcy code is uniform at the federal level. Rather, the instrument makes use of the fact that bankruptcy judges' interpretation of the law varies significantly (LoPucki and Whitford (1993); Bris et al. (2006); Chang and Schoar (2013)).

Bankruptcy judges work in 276 divisional offices across the United States, each of which pertains to one of 94 US Bankruptcy Districts. A firm filing for bankruptcy may choose to file either where it is (1) headquartered, (2) incorporated or (3) does most of its business, thereby giving the largest firms some leeway in the bankruptcy venue. However, once a filing is made in a particular division, judge assignment is random. ${ }^{38}$ We can then rely on this random assignment to generate exogenous variation in the probability that a given case is converted, since judges vary in their propensity to convert filings. To implement the instrumental variables approach, we estimate the following first stage regression:

$$
\text { Liquidation }_{p, i, t}=\rho+\pi \cdot \phi_{j}+\lambda X_{p, i, t}+\delta_{d, t}+\mu_{k}+\epsilon_{p, i, t}
$$

where Liquidation $_{p, i, t}$ is an indicator variable equal to one if the bankruptcy case was converted to Chapter 7 liquidation and zero otherwise. Importantly, we include division by year fixed effects, $\delta_{d, t}$, to ensure that we exploit judge random variation within a division-year. We also include plantlevel controls $X_{p, i, t}$ and industry fixed effects, $\mu_{k}$. The coefficient on the instrumental variable, $\pi$, represents the impact of judge $j$ 's tendency to convert a case to Chapter $7, \phi_{j}$, on the probability that a case is converted to Chapter 7 liquidation. We estimate $\phi_{j}$ as the share of Chapter 11 cases

\footnotetext{
${ }^{36}$ To verify this, we examined the court documents of 200 randomly selected cases in our sample, and found that for the median case the time between case filing and a decision on whether the case will remain in Chapter 11 or be converted to Chapter 7 is 4 months.

${ }^{37}$ This approach was pioneered by Kling (2006), and has been applied in a variety of settings (Doyle Jr (2007); Doyle Jr. (2008); Maestas et al. (2013b); Di Tella and Schargrodsky (2013); Dahl et al. (2014); Galasso and Schankerman (2015); Chang and Schoar (2013); Dobbie and Song (2015)).

${ }^{38}$ As an example, consider the bankruptcy district of New Jersey, which is divided into 3 divisions: Camden, Newark, and Trenton. The Local Rules of the New Jersey Bankruptcy Court lay out exactly which counties pertain to each division, and firms must file in the division "in which the debtor has its principal place of business." Once a case is filed in a particular division, the Local Rules state that "case assignments shall be made by the random draw method used by the Court."
} 
that judge $j$ ever converted to Chapter 7, excluding the current case. This standard leave-one-out measure deals with the mechanical relationship that would otherwise exist between the instrument and the conversion decision for a given case and follows the previous literature that uses the random assignment of judges as an instrument (e.g., Doyle Jr (2007), Maestas et al. (2013a), Galasso and Schankerman (2015) among others). ${ }^{39}$ The second stage equation estimates the effect of liquidation on plant outcomes:

$$
Y_{p, i, t+k}=\alpha+\beta \cdot \text { Liquidation }_{p, i, t}+\gamma X_{p, i, t}+\delta_{d, t}+\mu_{k}+\epsilon_{p, i, t+k}
$$

where Liquidation $_{p, i, t}$ are the predicted values from the first stage regression. In all regressions we cluster standard errors at the division-by-year level, to account for any correlation within bankruptcy court.

If the conditions for a valid instrumental variable are met, $\beta$ captures the causal effect of Chapter 7 liquidation on plant outcomes and asset allocation, relative to reorganization. It is important to note that the estimates in the instrumental variables analysis are coming only from the sensitive firms - those firms which switch bankruptcy regimes because they were randomly assigned a judge that commonly converts cases (Imbens and Angrist (1994)). Clearly, there are some firms that will stay in Chapter 11 no matter the judge and there are other firms that will convert to Chapter 7 regardless of the judge. Thus, the instrumental variables estimates only capture the local average treatment effect on the sensitive firms, and should be interpreted as such. We discuss the set of sensitive firms in our sample below.

\section{B. Judge Heterogeneity and Conversion to Liquidation}

For the instrument to be valid, it must strongly affect the likelihood of conversion to Chapter 7 liquidation. This can be illustrated in Figure 4, which plots the nonparametric kernel regression between the probability that a case is converted to liquidation and $\phi_{j}$, the share of Chapter 11 cases that a judge ever converted, after purging both variables for division-year fixed effects, industry fixed effects, and all control variables in $X_{p, i, t}$. We confirm this evidence in our first stage regression, presented in Table 3, which demonstrates that there is a strong and tightly estimated relationship between the instrument and the probability of conversion to liquidation, even after introducing a comprehensive set of controls.

\footnotetext{
${ }^{39}$ In Table A.2 in the Appendix we show that the results are unchanged if we define the instrument as the share of cases that judge $j$ converted to Chapter 7 in the five years prior to the current case. We also show that judge leniency is quite consistent over time, as judge decisions in the first half of their tenure strongly predict their decisions in the second half of their tenure with a coefficient close to one, as shown in panel C of Appendix Table A.2. This further motivates the use of the standard leave-one-out measure of judge leniency in the main analysis.
} 
In column 1 of Table 3 the unit of observation is a bankruptcy filing. The result illustrates that the instrument, share of other cases converted, is strongly and significantly correlated with conversions to liquidation. In particular, a one standard deviation (12.9\%) increase in our instrument increases the likelihood of conversion by $7.49 \%$, a $18.37 \%$ increase from the unconditional propensity of $40.74 \%$.

In the remaining columns of Table 3, and in fact in the entire analysis below, the unit of observation is at the plant location level rather than the bankruptcy case level. In these regressions each observation is weighted by the inverse of the number of plants operated by the firm, to ensure that each firm receives the same weight in the regression and to avoid overweighting large bankruptcy cases. In column 2 we repeat the specification in column 1, and verify that the first stage results are identical to column 1 in which the unit of observation is at the bankruptcy case level. In column 3 we add additional control variables, such as the plant age and number of employees per plant at the year of the bankruptcy filing. ${ }^{40}$ The results remain unchanged. In Table A.2 of the Appendix we illustrate that the results are robust to alternative instrumental variable specifications discussed above. In all specifications, the F-stat is above 100, well above the required threshold of $F=10$ to alleviate concerns about weak instruments (Staiger and Stock (1997)).

Another identifying assumption is monotonicity, which requires that the assignment of a judge has a monotonic impact on the probability that a given Chapter 11 case is converted into Chapter 7. This means that while the instrument may have no effect on some firms, all those who are affected are affected in the same way. The assumption would be violated if we observe certain types of firms for which the likelihood of conversion increases after being assigned to a given judge, and other firms treated with the same judge for which the likelihood of conversion decreases. This implies that the first stage estimates should be non-negative for all subsamples. In unreported regressions, we estimate the first stage regression for samples split by the median for the following characteristics: number of employees at plant or firm, number of plants in firm, county, or industry, plant age, three-year employment growth in county or industry, and payroll per employee in county or industry. We also estimated the first stage separately for multi-state and multi-county firms and single-state and single-county firms, since firms in multiple counties or states might be able to "forum shop" for a different bankruptcy venue. As we can see from Table A.3 in the Appendix, the estimates are positive and sizable in all subsamples, in line with the monotonicity assumption. We

\footnotetext{
${ }^{40}$ Surprisingly, $\ln$ (employees at plant) is positively related to the likelihood of liquidation, while $\ln$ (total employees at firm) is negatively related. This is because these two covariates are the same for all single-establishment firms in our sample, making them somewhat multi-collinear. If ln(total employees at firm) is omitted from the regression, the coefficient on $\ln$ (employees at plant) becomes negative and significant, as expected. However, the instrument is orthogonal to both of these variables, so it is unaffected by either of these controls, and we include both in order to control for plant-level and firm-level characteristics in the second stage.
} 
test the first stage on further subsamples as discussed in the next section, and continue to find that the coefficient is positive in all sample splits.

\section{Characterizing Marginal Firms in the Bankruptcy System}

In this section, we characterize the marginal firms in the bankruptcy system by running the first stage regression on various subsets of the data. This analysis accomplishes two goals. First, it helps with understanding the scope of the local average treatment effects of our analysis, by exploring which firms are likely to be sensitive to the instrument. Second, from a policy perspective it shows which firms would be most affected by a policy change in bankruptcy.

As pointed out by Maestas et al. (2013b), when the treatment variable is binary and the instrument varies between 0 to 1 , the size of the population that is marginal is equal to the first stage coefficient. In our case, moving from the most lenient judge, who converts zero cases, to the most strict, who converts all cases, would shift $58.1 \%$ of firms into liquidation, because the coefficient on share converted is 0.581 , as illustrated in Table $3 .{ }^{41}$ Building on this insight, by running the first stage regression on different subsamples we can determine the share of firms in each category that are "compliers" - that is, firms that are sensitive to the judge assigned to the case. Table 4 gives a summary of our findings.

We first split by size of the firm, looking at firms with 0-5 employees, 6-25 employees, 26-100 employees, 101-1,000 employees, and 1,000+ employees. Among these groups, the raw share of firms converted to liquidation, as noted in column 3 , is $44 \%, 44 \%, 41 \%, 29 \%$, and $13 \%$, respectively, showing even among larger firms a substantial number are liquidated. In column 4 we display the coefficient on share converted from the first stage regression. With the exception of firms over 1,000 employees, the coefficient is large and highly significant for each subgroup, demonstrating that a high proportion of firms with less than 1,000 employees is sensitive to judge biases. Interestingly, the share of firms that are marginal is non-monotonic in size. Just under $50 \%$ of firms with $0-5$ employees are sensitive to judge assignment, and this proportion grows to $88 \%$ of firms with 26-100 employees. The proportion then decreases again, such that $52 \%$ of firms with 101-1,000 employees are compliers, and only $26 \%$ of firms with over 1,000 employees are sensitive to the judge. It is perhaps unsurprising that only few of the largest firms are compliers, as only $13 \%$ of these firms are converted to Chapter 7 overall and presumably the stakes are large enough in these cases that judicial preferences are of less consequence. ${ }^{42}$ However, we also point out that our sample contains

\footnotetext{
${ }^{41}$ Of course, moving from the most lenient to the most strict judge is an extreme shift and is only a hypothetical exercise. Because most judges are near the center of the distribution, randomly reassigning firms to judges would result in far fewer firms moving to other bankruptcy regimes.

${ }^{42}$ When firms of this size liquidate, it is more common for them to do so within Chapter 11, rather than converting to Chapter 7.
} 
only 1000 firms with over 1,000 employees, and for this reason there is not much statistical power to identify the effect of the judge after the inclusion of division by year fixed effects.

We can also estimate the share of firms that would always be converted to liquidation regardless of the judge. We estimate this share of "always takers" by using the first stage regression coefficients to predict the probability of liquidation if $\phi_{j}=0$, meaning the firm was assigned to the most lenient judge in the sample. We then average the predicted probability of liquidation under the most lenient judge to estimate the share of always takers in each subgroup. ${ }^{43}$ The findings are both intuitive and interesting. In column 6, we find that the smallest firms have the highest share of always takers, consistent with the intuition that the smallest firms are the least likely to need Chapter 11 protection. Meanwhile, the fraction of always takers declines substantially for all firms with more than 25 employees.

Combining this with the analysis of the share of compliers in column 4 , we can characterize the different size categories as follows. Among firms with less than 25 employees, about one quarter are converted to liquidation regardless of the judge and about half are marginal. Nearly all of the middle-sized firms are compliers, with only about $6 \%$ being always takers and an additional $6 \%$ being "never takers" - firms that would not be converted even under the strictest judge. Meanwhile, hardly any of the largest firms are always takers and a relatively small portion are compliers, leaving a large fraction of never takers.

Table 4 also displays first stage coefficients and the percentage of always takers for the sample splits of market thickness and access to finance. We find little difference in the first stage when we split by market thickness, with a $55.7 \%$ (19\%) share of compliers (always takers) in thick markets compared to $60.3 \%(16 \%)$ in thin markets. On the other hand, we see slightly larger differences when we split the sample by access to finance, where $66.4 \%$ of firms are sensitive to the judge assignment in markets with high access to finance (14\% always takers) compared to $48.4 \%$ in low access to finance areas (23\% always takers).

\section{The Exclusion Restriction Condition}

Our identification strategy is designed to overcome the fact that selection into liquidation is endogenous. For the instrument to be valid, it must not only strongly affect the probability of conversion to liquidation, but also, importantly, must satisfy the exclusion restriction condition. Specifically, it is required that judge assignment only affects the outcomes of interest (e.g. whether a plant location is occupied five years after bankruptcy filing) via its impact on the probability that a case

\footnotetext{
${ }^{43}$ The proportion of firms that would not be converted even under the strictest judge ("never takers") can be easily calculated as 1 - (\% always takers) - (\% compliers). For example, in the full sample, we estimate that $18 \%$ are always takers, $58 \%$ are compliers, and $24 \%$ are never takers.
} 
is converted to liquidation. As evidence in partial support of our identification assumption, Table 5 reports randomization tests that show that our instrument is uncorrelated with a comprehensive set of firm and plant level characteristics, as well as local and industry conditions.

Column 1 of Table 5 shows that the $R^{2}$ when we regress $\phi_{j}$ on the full set of division by year fixed effects and no other controls is 0.777 , suggesting that there is substantial variation in judge conversion propensities between divisions and over time. In the next column, we explore whether within a division-year such variation is correlated with bankruptcy case characteristics by adding controls for plant size and age, firm size, an indicator for whether there were multiple associated bankruptcy filings, and industry fixed effects. None of these variables is statistically significant and the $R^{2}$ is unaffected by their addition. In column 3 we include pre-trends in employment at the bankrupt plant for 3 years prior to the bankruptcy filing. These employment figures are calculated by using the address matching algorithm discussed in Section IV.A to calculate total employment at a location prior to bankruptcy even if it was not owned by the bankrupt firm. As can be seen, we find no evidence that judge leniency is correlated with these pre-trends. We provide further evidence for the lack of pre-trends in Figure 5, which displays the reduced-form results in the years around the bankruptcy filing. In all cases, $\phi_{j}$ is uncorrelated with utilization in the years prior to the bankruptcy filing.

The next columns in Table 5 explore whether local market conditions are correlated with the instrument. In columns 4, 5, and 6 we separately add dummy variables indicating if a plant was in a county with above-median market thickness (as defined in Section III), share of small business loans (also defined in Section III), or three-year cumulative employment growth prior to the bankruptcy. In column 7 we add all three measures together. In none of the specifications are any of these measures statistically significant. In column 8 we also add additional variables that capture local economic activity and industry conditions such as the number of plants in the county and industry, payroll per employee in the county and industry, and three-year employment growth in an industry. Once again, all controls are insignificant and the overall $R^{2}$ remains basically unchanged. The evidence in Table 5 suggests that there is indeed random assignment of judges to bankruptcy filings within court divisions, thus alleviating the concern that $\phi_{j}$ might be related to other factors that might influence future plant outcomes.

The exclusion restriction assumption might still be violated if judge leniency affects plant outcomes through channels other than the bankruptcy regime. At this point, it is important to clarify the definition of the liquidation treatment in our setting. It may be the case that in the economy, the motion of Chapter 7 conversion is systematically correlated with other motions, or may systematically be approved by judges with particular characteristics. If this is how firms are liquidated 
in the economy, then naturally this is also the liquidation treatment in our setting. We cannot separate the law from the way it is implemented. In that case, the liquidation treatment should be viewed more broadly than just the motion to convert to Chapter 7 , but rather as the package of motions and judge characteristics that typically lead to conversion, and the results should be interpreted accordingly. Below, we attempt to explore the extent to which this broader interpretation is warranted.

We first estimate reduced-form regressions which directly relate judge leniency, $\phi_{j}$, to plant outcomes:

$$
Y_{p, i, t+k}=\alpha+\beta \cdot \phi_{j}+\gamma X_{p, i, t}+\delta_{d, t}+\mu_{k}+\epsilon_{p, i, t+k}
$$

These regressions, reported in Table A.4 in the Appendix, illustrate a strong relationship between the instrument, $\phi_{j}$, and $Y_{p, i, t+k}$ for all of our outcome variables. Arguably, this is because judge leniency leads to liquidation, which subsequently affects asset reallocation. However, if $\phi_{j}$ is systematically correlated with judge skill or other judge attributes that affect asset allocation outside of the bankruptcy regime, then $\phi_{j}$ should affect $Y_{p, i, t+k}$ also when limiting the sample only to firms that remain in reorganization, or only to firms that are liquidated. As reported in Table A.5 in the Appendix, when we run reduced-form regressions on these two subsets of firms we find no significant relationship between the instrument and plant outcomes, however. In column 7 of Table A.5, we also find that within Chapter 11 reorganization, $\phi_{j}$ is uncorrelated with bankruptcy refiling rates, a proxy for bankruptcy resolution success which may depend on judge skill. This suggests that other judge characteristics or tendencies that may be correlated with $\phi_{j}$ do not affect plant outcomes outside of the bankruptcy regime.

In further support of this, we also examine whether judges have a large effect on bankruptcy cases before making a decision on whether to convert a case or not. Based on a random sample of 200 cases, we calculate that the median time between the bankruptcy filing and the selection of the bankruptcy regime (either liquidation or reorganization) is only 4 months. Further, we find that typically no significant motions are passed in the case prior to a ruling on a motion to convert the case. Lastly, we also note that Chang and Schoar (2013), who use detailed data on court motions to perform a principal component analysis on a set of the most important rulings of a bankruptcy judge in an effort to identify pro-debtor judges, find that the motion to convert a case receives by far the lowest weight in the first principal component. This suggests that the decision to convert may be mostly unrelated to a judge's overall pro-debtor or pro-creditor bias, as opposed to other motions. Hence, while we cannot fully reject the broader interpretation of the liquidation treatment, we find no evidence for its existence in affecting asset allocation and utilization. 


\section{Results}

\section{A. Main Results}

We first focus on how liquidation affects reallocation and utilization in the full sample by testing its impact on four main outcome variables. Continues is an indicator variable equal to one if the plant is active (has positive payroll) and continues to be occupied by the original bankrupt firm five years after the bankruptcy filing. The purpose of this variable is to explore the extent to which liquidation forces more discontinuation than reorganization. Related to the Continues variable is Holding Time, defined as the number of years until a plant is no longer occupied by the original bankrupt firm (either reallocated to a new user, or reallocated to vacancy). ${ }^{44}$ As discussed in the theoretical framework in Section II, this variable conveys the extent to which liquidation speeds up the discontinuation of a plant versus reorganization. Finally, we examine two measures of utilization of real estate assets, regardless of who the occupant is. Occupied is an indicator equal to one if the asset is occupied five years after the bankruptcy filing. Ln(average employment) is defined as the average employment at a specific location over the five years after the bankruptcy filing. Because vacant establishments by definition have zero employment and payrolls, this employment measure accounts for any interim years in which a plant is not occupied, even if it is occupied in year five. Further, it has the advantage of accounting for the intensive margin of employment as well as the extensive margin, since it reflects plants that are reallocated but have fewer employees. For both measures of utilization, the geographical linkages discussed in Section IV.A allow us to account for reallocation of assets to new users.

Table 6 shows both OLS and 2SLS estimates of the impact of liquidation on these plant outcomes. $^{45}$ These regressions include all controls in column 3 of Table 3, including industry and division-by-year fixed effects. Regular OLS results, which do not account for selection, show that liquidation is associated with a $30 \%$ decrease in the likelihood of continuation five years after the bankruptcy filing. The 2SLS estimates in column 2, show that exogenously converting a firm to liquidation reduces the probability of continuation, with a magnitue of $32.4 \%$. In addition, columns 3 and 4 show that asset holding time is on average 1.7 years shorter in liquidation. These results are somewhat mechanical, since liquidation forces discontinuation while reorganization does not, and thus it is not surprising that it causes more discontinuation and speeds up the time until the asset is no longer used by the bankrupt firm. However, these findings are useful for three reasons. First,

\footnotetext{
${ }^{44}$ We cap Holding Time at 5 years to match the horizon in other variables. However, the results are unchanged if we set it to 7 or 10 years for these plants.

${ }^{45}$ As noted previously, observations are weighted by the inverse of the number of establishments in the bankrupt firm to avoid overweighting a few large bankruptcy cases. However, we find essentially identical results in unweighted OLS regressions.
} 
they validate that liquidation indeed causes increased shut down. Second, they demonstrate that reorganization leads to a significant amount of discontinuation as well. Indeed, given that liquidation forces discontinuation, it is somewhat surprising that only $32.4 \%$ more firms are discontinued in liquidation than reorganization. Third, the holding time result relates directly to the theoretical framework, showing that forced sales do indeed speed up discontinuation as predicted by the model. We return to this prediction in the heterogeneity analysis below.

The main findings of the paper relate to the utilization of the location regardless of the owner, as captured by occupied and $\ln$ (average employment) in columns 5-8 of Table 6 . Across all specifications, we find that liquidation leads to a significant decline in asset utilization 5 years after the bankruptcy filing. 2SLS estimates show that liquidation reduces occupancy rates by $17.4 \%$, an effect that is both statistically and economically significant. ${ }^{46}$ This estimate is roughly half the size of the $32.4 \%$ decline in plant continuation, demonstrating that reallocation to new users closes some of the gap between liquidation and reorganization, but not entirely.

The magnitude of the decline is even larger when measuring by employment, estimated at $34 \%$ in column $8 .^{47}$ This suggests that not only does liquidation reduce occupancy rates on average (the extensive margin), but it also reduces employment, which proxies for the extent to which an occupied asset is used. ${ }^{48}$

While Table 6 focuses on outcomes in year 5 after the bankruptcy, the effect of liquidation on occupancy and employment is apparent quite quickly after bankruptcy. This can be seen in Figure 5 , which shows coefficients from reduced-form regressions over a time horizon from three years prior to five years after the bankruptcy filing. As shown in Panels (a) and (b), liquidation leads to a decline in both occupancy and employment in the first year after banrkuptcy, and this drop is quite stable over time. However, these results mask considerable heterogeneity across markets, which we discuss in the next section. ${ }^{49}$

Taken together, the results show that bankruptcy regimes importantly affect asset allocation and subsequent utilization. In liquidation, plants are more likely to be discontinued, as expected,

\footnotetext{
${ }^{46}$ It is also interesting to note the gap between the OLS and IV estimates, which capture the selection into treatment. While there is clearly selection into Chapter 7 liquidation, how this selection might bias OLS estimates is ex ante unclear. On one hand, it is likely that poorly-performing firms will be more likely to be converted, and their assets are less likely to be reallocated, which would bias OLS coefficients downwards. On the other hand, firms with assets that will be easily redeployed may be more likely to move to liquidation, which would bias OLS coefficients upwards. Results in Table 6 suggest that to a large extent these two effect balance each other out, so that OLS estimates are similar to 2SLS.

${ }^{47}$ Since these are log-linear models with the independent variable of interest, Liquidation $_{p, i, t}$, being a dummy variable, the estimated impact of moving from reorganization to liquidation is $100[\exp (\beta)-1]$.

${ }^{48}$ In fact, focusing on manufacturing firms only, we find that liquidaiton reduces productivity as reported in Table A.12 in the Appendix. However, this analysis is fairly suggestive due to data limitations, as we discuss in Section A in the Appendix.

${ }^{49}$ Appendix Table A.7, which displays dynamic 2SLS coefficient estimates instead of the reduced-form coefficents, also shows that liquidation leads to lower overall wages at the plant.
} 
but these assets are not fully reallocated, such that assets in liquidation exhibit lower utilization relative to reorganization, as measured by either occupancy or employment.

\section{B. The Role of Market Thickness and Access to Finance}

The results presented so far show that liquidation causes significantly faster discontinuation and lower asset utilization five years after the bankruptcy filing. In this section, we explore how the gap between liquidation and reorganization is related to the market in which bankruptcy occurs. In particular, we focus on two local market characteristics (described in Section III above) that theory predicts affect asset reallocation: market thickness and access to finance.

In Table 7, we split the sample based on the market thickness measure, in which we define "thick" industry-county-year triplets as those having above-median Thicknessict, and then run our IV specifications separately for plants in thick and thin markets. We also display results in which we interact liquidation with this thick market dummy, and correspondingly we interact share converted with thick market in the first stage so that we have two endogenous variables and two instruments. To allow full flexibility, we interact all other covariates with thick market as well. With this setup, the coefficient on liquidation*thick market tests whether the effect of liquidation is significantly different in thick markets versus thin markets. ${ }^{50}$

The first three columns of Panel A show that in both thick and thin markets liquidation reduces the probability that a plant will continue with the original bankrupt firm by a similar amount. However, columns 4-6 show that this discontinuation is faster in liquidation in thin asset markets. In thick markets, reorganized plants are held by the original owner for 1.4 more years than liquidated plants, while in thin markets the gap is $29 \%$ larger at 1.8 years. ${ }^{51}$ This is consistent with the dynamic search model in Section II, which predicts that liquidation leads to a quicker reallocation of assets in particular in thin markets. In these markets, reorganized firms can be patient as they wait to find a new user, while liquidated plants are forced to try to locate new users despite high search costs.

Panel B of Table 7 shows that the differences in asset utilization between thick and thin markets are stark. In column 1, we find that asset reallocation in thick markets allows the occupancy rate of liquidated plants to be similar to that of reorganized plants, despite the high level of discontinuation in liquidation shown in Panel A. Thus, the null hypothesis of no difference between

\footnotetext{
${ }^{50}$ Note that we do not claim that plants are exogenously distributed across thick or thin markets. By running the regressions on separate sub-samples (or fully interacted), we compare thick-market firms that are randomly assigned to "liquidating judges" to those that are assigned to "reorganizing judges," and similarly we compare thin-market firms that are randomly liquidated to those that are not. Thus within each regression the estimates can still be interpreted as causal, and the comparison across regressions sheds light on which markets are driving the overall effects.

${ }^{51}$ While the difference in holding times is economically important, the gap is not statistically significant.
} 
the two bankruptcy regimes is not rejected, as the market fully absorbs the increased numbers of discontinued plants in liquidation. Meanwhile, column 2 shows that occupancy rates for liquidated plants are $32.4 \%$ lower in thin asset markets, relative to plants that are reorganized in thin markets. Hence, in contrast to thick markets, liquidated plants do not seem to reallocate to new uses at higher rates than reorganized plants. ${ }^{52}$ Column 3 shows that the difference between the two markets is statistically significant. Similarly, in comparing columns 4 and 5 we find that in thick markets liquidation does not have a significant effect on average employment (indeed, the coefficient estimate is even positive), but in thin markets liquidation reduces employment by 54.6\%. Again, this difference between the two markets is statistically different. Overall, the effect of liquidation on asset utilization is entirely concentrated in thin markets, while reallocation in thick markets results in liquidation having no impact on utilization. These results are consistent with the theoretical framework in Section II that highlights the implications of search frictions and thin markets on asset reallocation (Williamson (1988); Gavazza (2011))..$^{53}$

Similar to market thickness, access to finance can affect asset allocation and utilization in bankruptcy regimes by limiting the set of potential users (Shleifer and Vishny (1992)). In Table 8 we present regression results similar to Table 7 , except here we split our sample based on access to capital in the local market. We proxy for access to finance by measuring for each county the share of loans given to small businesses, defined as firms with $\$ 1$ million or less in annual gross revenue. ${ }^{54}$ In all cases, we find similar results as those for market thickness. Specifically, in markets with low access to finance liquidation reduces holding times by 2 years, while in areas with high access to finance the gap is 1.4 years. Further, we see no decline in occupancy or employment in markets with high access to finance, but $45 \%$ lower occupancy and $69 \%$ lower employment in areas with low access to capital. This supports the theory that search costs, and access to capital in particular, are a key determinant in the ability to reallocate bankrupt assets. ${ }^{55}$

\footnotetext{
${ }^{52}$ Indeed, the coefficient estimate of liquidation's impact on continuation in thin markets (Column 2, -32.1\%) is almost identical to its impact on occupancy (Column 4,-32.4\%). This does not mean, however, that there is no reallocation of liquidated plants in thin markets. Rather, it shows that the reallocation of assets increases the occupancy of both reorganized and liquidated plants at similar rates in thin markets.

${ }^{53}$ These results are robust to using an alternative measure of market thickness, that is, local commercial real estate transactions per capita. This measure aims to capture the liquidity of the local commercial real estate market. We construct this measure using the CoreLogic dataset by dividing the total number of real estate transactions in a county by the county population. The results are discussed in detail in the Appendix, and reported in Panel A of Table A.11 in the Appendix.

${ }^{54}$ Loan data comes from the Community Reinvestment Act (CRA) disclosure data and is only available beginning in 1996, which removes about 30,000 plants from our sample that filed for bankruptcy prior to 1996. Note that the CRA data is based on the location of the loan recipient rather than the location of the bank, and thus the bank is not necessarily located in the same county. However, the 2003 Survey of Small Business Finances shows that bank loan markets tend to be quite local, as over $70 \%$ of firms borrow from banks located less than 20 miles away.

${ }^{55}$ We find similar results when using an alternative measure of local access to finance, that is, the share of bank deposits in a county held small banks. This variable stems from the idea that small, local banks are the principle providers of capital for small firms (Petersen and Rajan (1994)). Hence, a higher concentration of deposits in local
} 
In Panels (c) - (f) of Figure 5, we examine how the effect of liquidation evolves dynamically in markets with high and low search costs. These figures show the coefficients from reduced form regressions where we interact the instrument with dummy variables of high and low search costs for market thickness and access to finance respectively. Importantly, we find no pre-trends in occupancy or employment for any of these sample splits. In the post-bankruptcy period, Panels (c) and (d) show that liquidation in thick markets causes an initial drop in utilization in year 1 , but that this gap disappears by year 2 , consistent with low search costs enabling asset reallocation after the liquidated firm is shut down. However, the drop in utilization caused by liquidation slightly increases over time in thin markets, where search costs are high. A similar pattern emerges in Panels (e) and (f), where we split by areas with high and low access to finance. ${ }^{56}$

Whether we proxy for search costs with market thickness or access to finance, we find support for the theoretical predictions outlined above. Importantly, market thickness is uncorrelated with access to finance, as shown in Appendix Table A.10, suggesting that each channel is separate and exerts a significant effect individually. These results are robust when using alternative measures of market thickness and access to capital, as described in Appendix Section A. We have also performed several additional robustness tests in unreported results. For example, we find essentially identical results if we split by market thickness within industry-year, showing that the results are not driven by certain industries or by time-series variation, but rather by geographic variation within industry. The results are not driven by rural counties with few potential buyers. Dropping all counties with less than 20,000 employees (the 10th percentile in our sample) does not affect the results. Further, splitting the sample by a measure of industry agglomeration developed by Ellison and Glaeser (1997), which is similar to our Thickness ${ }_{i c t}$ measure but explicitly adjusts for county size, shows similar results. In addition, scaling access to capital on a per capita basis, rather than market share, does not affect the results.

\section{External Validity and Economic Importance}

While our results show that liquidation has a large impact on the long-term utilization of bankrupt locations, the aggregate economic importance of these findings could be small if only the smallest firms are liquidated, or few firms are at the margin between the two bankruptcy procedures. This section discusses the external validity of our results and their overall economic importance.

In Section V.C above, we have already shown that over 40\% of firms with less than 100 employees

small banks is likely to provide higher access to capital to small businesses. We discuss the construction of the measure in the Appendix, and report the results in Panel C of Table A.11 in the Appendix.

${ }^{56}$ For robustness, Appendix Figure A.1 displays similar results using a binary version of our instrument in reducedform regressions with no other controls or fixed effects. 
are converted to liquidation, and even among firms with 100-1,000 employees $29 \%$ are liquidated. Further, we estimate that moving from the most lenient to the most strict judge would shift between $49 \%$ and $88 \%$ of all firms with fewer than 1,000 employees to liquidation, suggesting that the majority of firms with less than 1,000 employees are marginal in the sense that whether they end up in reorganization or liquidation depends on judge assignment. This corroborates Bris et al. (2006), who find that there is considerable overlap in the size of Chapter 7 and Chapter 11 firms, and that "a good number of firms could have chosen either procedure."

Further, firms with less than 1,000 employees constitute a significant portion of the U.S. economy. Using data from the full LBD, we find that firms with less than 1,000 employees compose 99.8\% of all firms between 1992 and 2005 (our sample period). These firms employ 55\% of all workers and, more importantly for this study, occupy $85 \%$ of all business locations in the U.S. Thus, a large portion of the assets in the economy are held by firms that could marginally be placed in liquidation or reorganization.

A second important point is that many firms in the U.S. file directly for Chapter 7. According to U.S. Court filing statistics, direct-to-Chapter-7 filings account for $72 \%$ of all non-farm business bankruptcies, while Chapter 11 filings make up the remaining $28 \% .{ }^{57}$ For identification purposes, our sample is composed only of firms that file for Chapter 11 (of which $40 \%$ are subsequently converted to Chapter 7), but to the extent that all firms in Chapter 7 face search costs when liquidated, our results can be interpreted more broadly.

\section{Efficiency Discussion}

While the empirical results in the paper demonstrate that liquidation leads to lower utilization in thin markets and markets with low access to finance, the question remains whether this gap in utilization is caused by inefficient liquidation or inefficient continuation of reorganized firms. On the one hand, liquidation may lead to under-utilization if reallocation is hampered by high search costs due to thin markets (Williamson (1988); Gavazza (2011)), or financial constraints (Shleifer and Vishny (1992)). Alternatively, it might be the case that assets are over-utilized in thin markets due to agency costs that lead to the inefficient continuation of reorganized firms (Franks and Torous (1989); Gertner and Scharfstein (1991); Bolton and Scharfstein (1996); Hotchkiss (1995)). In this section we conduct several tests, both theoretical and empirical, to explore whether the results arise through inefficient reorganization or inefficient liquidation. Importantly, this discussion is focused

\footnotetext{
${ }^{57}$ In Appendix Table A.1 we present summary statistics for a sample of firms that filed directly for Chapter 7 that we matched to the LBD. The average Chapter 7 firm employs 20.4 workers and occupies 1.4 locations, which is significantly smaller than the average Chapter 11 firm, but not negligible in the aggregate.
} 
exclusively on the efficiency of the ex post asset allocation of each bankruptcy procedure. Other costs and benefits of liquidation and reorganization, including legal fees, creditor recoveries, and worker outcomes, play an important role in the overall welfare implications of each bankruptcy regime, but are not considered here.

\section{A. Agency Costs and Asset Allocation}

Although we cannot completely determine whether liquidation is associated with inefficiently low levels of utilization or reorganization leads to inefficiently high levels of utilization, we have some evidence against the latter. In particular, the main argument for liquidation being efficient is that it leads to an improved allocation of assets once a match is found, even if this comes at a cost of leaving an asset vacant for a period of time. Meanwhile, assets in reorganization might be prevented from reallocating to better uses due to agency costs. If this is the case, then we should see that the utilization of liquidated assets is higher than that of reorganized assets once a match has been found and the location has been reallocated. Following this logic, if agency costs are high we would expect the utilization of liquidated assets to be higher in thick asset markets where reallocation happens relatively quickly for these assets. However, this is inconsistent with the empirical findings.

The dynamic search model described in Section II, and developed formally in Appendix B, formalizes this intuition. The model incorporates both search frictions and agency costs, and also includes the time dynamics that capture the opportunity cost of waiting for future potential users. As illustrated in Figure 1, our empirical evidence fully supports the model predictions when agency problems are modest.

Figure 2 illustrates how the model's predictions change when agency costs become significant. ${ }^{58}$ Panels (a) and (b) show that, when agency costs are significant, only reorganized sellers with particularly low productivity become active sellers, due to their desire to retain the asset. This affects the holding time as illustrated in panels (c) and (d), where the holding time increases for every level of market thickness when agency costs are high. Therefore, increasing agency costs increases the fraction of low-productivity reorganized sellers that continue to hold the assets inefficiently. ${ }^{59}$

Most strikingly, significant agency costs lead to different predictions with respect to asset utilization and productivity of asset users over time. As illustrated by Panel (f) of Figure 2, when agency costs are significant, the utilization of the reorganized assets is lower than liquidation, even in thin markets, and as the market becomes thicker, the gap between liquidation and reorganization

\footnotetext{
${ }^{58}$ We formally derive the model, and discuss the construction of the numerical illustration in Section $\mathrm{B}$ of the Appendix.

${ }^{59}$ Note that in panels (c) and (d) we plot the log of holding time to easily compare high and low agency costs using the same y-axis scale.
} 
increases and there is no crossing-point between the two curves. This is the case since liquidated sellers reallocate the asset to new and more productive buyers while reorganized sellers are unwilling to do so, even when their productivity is particularly low.

Due to agency costs, reorganized sellers are insulated from the market and thus less responsive to reductions in search costs, which leads to the increase in the gap in utilization. This is inconsistent with the empirical evidence, however, as we find that on average reorganization leads to higher utilization in thin markets, and the gap is decreasing in market thickness such that empirically we find no significant differences between liquidated and reorganized sellers in thick markets, equivalent to the cross-point between the utilization curves. These empirical results are consistent with low agency costs as illustrated in Panel (e), in which there is a crossing point when markets become thicker. A similar picture arises with the average productivity of the users of the assets, as illustrated in Panels (g) and (h).

The model highlights that our empirical findings are inconsistent with large agency costs preventing assets from reallocating in reorganization. We should note, however, that this does not suggest that agency costs are not important in bankruptcy. Indeed, agency costs are likely to be significant in the very largest bankruptcy cases with complex capital structures. But liquidation in these large firms is uncommon, as shown in Section V.C. Instead, our results, which focus on the large set of firms that are on the margin between the two bankruptcy regimes, suggest that search frictions loom larger than agency costs. Therefore, inefficient allocation of assets is likely to occur in thin markets when firms are liquidated and experience high search costs.

\section{B. Opportunity Cost and Local Vacancies}

From an empirical standpoint, understanding whether an asset is efficiently vacant or under-utilized is challenging because of the difficulty in measuring its opportunity cost. However, it is important to note that the random assignment of judges in the empirical strategy effectively allows us to compare plants with similar opportunity costs. Specifically, since the assets' opportunity cost is orthogonal to the judge leniency to convert cases to Chapter 7 (as all other characteristics), it can be viewed as if the liquidation treatment occurs while holding opportunity cost constant. Therefore, the lower utilization caused by liquidation relative to reorganization is arguably independent of the opportunity cost of the asset.

However, it might still be the case that liquidation causes lower utilization only in areas where the opportunity cost of utilizing the assets is low, and that this is driving our overall estimates. For example, liquidation could lead to high vacancy rates but have little impact on overall efficiency if local availability of space is high. This suggests a natural proxy for the oppotunity cost of vacancy: 
the utilization of non-bankrupt local establishments. In particular, we posit that the opportunity cost of leaving a location vacant depends on the overall vacancy rate of the local area. ${ }^{60}$ In areas with low vacancy rates, the opportunity cost of leaving a location vacant should be high since there is relatively high demand for real estate. Meanwhile, areas with high vacancy will have low opportunity costs of vacancy since firms may have many alternative locations to move into. Under this assumption, if we find that liquidation causes a drop in utilization even in areas with low vacancy (high opportunity cost) then it provides further evidence consistent with the inefficiency of liquidation.

In Figure 3 we compare the utilization of bankrupt locations relative to average local utilization of non-bankrupt plants, which proxies for the opportunity cost of vacancy. As can be seen, bankrupt assets are less likely to be occupied and utilized relative to average local plants for all five years after the bankruptcy. More importantly, liquidation is associated with significantly lower utilization relative to reorganization. This evidence suggests inefficient use of the assets relative to the local characteristics. $^{61}$

We directly test whether liquidation leads to vacancy only when opportunity costs are low in Table 9. In column 1 of Panel A, we show that our main 2SLS specification is unaffected when we control for an indicator equal to one if the bankrupt plant is in a county with high (above-median) benchmark utilization. Interestingly, this control strongly predicts the utilization of the bankrupt firm's asset. However, the coefficient of liquidation remains unchanged, which rules out an omitted variables bias in which the negative effect of liquidation stems from plants being left vacant in areas that already have low occupancy. Column 2 shows that the results with respect to market thickness are robust and unaffected by the control for local benchmark occupancy as well.

Even more telling is column 3, where we also include an interaction between the liquidation dummy and the high benchmark occupancy indicator. ${ }^{62}$ While the direct effect of high benchmark occupancy is statistically significant and predicts whether the bankrupt plant is utilized, we find that the coefficient on this interaction term is insignificant and near zero. This means that liquidation does not have a differential effect in areas with high benchmark occupancy, when the opportunity cost of vacancy is arguably low. This is important, as it shows that liquidation causes a decline in

\footnotetext{
${ }^{60}$ Grenadier $(1995,1996)$ finds that the level of equilibrium vacancy rates is predominately determined by local factors. Moreover, he illustrates a significant persistence in local vacancy rates in commercial real estate.

${ }^{61}$ We do not have an instrument for entering bankruptcy, and so this comparison with benchmark plants is only suggestive because it does not account for selection effects. For example, bankrupt buildings could remain vacant at higher rates because they are worse in some way. To the extent that these locations enter bankruptcy because the firms (and not the buildings) are bad, this is less of a concern. That is, as long as a building can be reallocated to a more-productive user, we should see utilization of these locations approach that of the overall economy.

${ }^{62}$ As before, when interaction terms are included in this second stage regression, we include the interaction of the share converted instrument and that variable in the first stage.
} 
utilization even in areas with high opportunity costs of vacancy. Columns 5 and 6 show further that the results regarding access to capital and liquidation are not dependent on benchmark occupancy either. Panel B demonstrates that all of the results with respect to employment are unaffected when controlling for benchmark utilization as well. ${ }^{63}$

Taken together, these results provide consistent evidence that our results are not driven by high-vacancy areas where the opportunity cost of leaving a location vacant are likely low. Instead, the evidence is consistent with the interpretation that liquidation causes vacancy even when the opportunity cost of doing so is high, making it less likely that this is an efficient outcome in thin markets. Of course, because we cannot directly measure asset efficiency, these results are not fully conclusive. However, they point towards the conclusion that liquidation leads to inefficient asset allocation and utilization in areas with high search costs.

\section{Conclusion}

How do institutions affect the allocation of assets in the economy? In this work we explore the role of the bankruptcy system in the allocation of the distressed firms' assets. In particular, we explore how liquidation and reorganization affect the allocation and subsequent utilization of the real estate assets used by bankrupt firms. We exploit the random assignment of judges to bankruptcy cases and variations in judges' interpretation of the law to instrument for the endogenous conversion of Chapter 11 filers into Chapter 7 liquidation. We create unique geographical linkages from the Census LBD database that allow us to track real estate utilization over time.

We find that liquidation leads to a significant reduction in the utilization of real estate assets on average, and this effect persists in the five years after the bankruptcy filing. These effects are fully concentrated in areas with high search costs such as thin asset markets where there are few potential users for bankrupt assets, and in areas with low access to finance. In contrast, in markets with low search frictions we find no differential effect of bankruptcy institutions on asset utilization. The results highlight the importance of local asset market frictions in the allocation of assets of firms in bankruptcy.

\footnotetext{
${ }^{63}$ All of the results also go through if we use as the benchmark only plants in the same county and 3-digit NAICS as the bankrupt plant. Further, the results are unchanged if we use the continuous benchmark occupancy rate rather than the above-median indicator as a control.
} 


\section{REFERENCES}

Aghion, Philippe, Oliver Hart, and John Moore, "The economics of bankruptcy reform," Journal of Law, Economics and Organization, 1992, 8 (3), 523-546.

Ayotte, Kenneth, "Leases and Executory Contracts in Chapter 11," Journal of Empirical Legal Studies, 2015, 12 (4), 637-663.

Baird, Douglas G, "The uneasy case for corporate reorganizations," The Journal of Legal Studies, 1986, 15 (1), 127-147.

_ , "Revisiting auctions in Chapter 11," Journal of Law and Economics, 1993, 36 (1), 633-653.

Bartelsman, Eric, John Haltiwanger, and Stefano Scarpetta, "Cross-country differences in productivity: The role of allocation and selection," The American Economic Review, 2013, 103 (1), 305-334.

Bebchuk, Lucian Ayre and Howard F Chang, "Bargaining and the division of value in corporate reorganization," Journal of Law, Economics, ES Organization, 1992, 8 (2), 253-279.

Benmelech, Efraim and Nittai K Bergman, "Bankruptcy and the collateral channel," The Journal of Finance, 2011, 66 (2), 337-378.

Bolton, Patrick and David S. Scharfstein, "Optimal debt structure and the number of creditors," The Journal of Political Economy, 1996, 104 (1), 1-25.

Bradley, Michael and Michael Rosenzweig, "The untenable case for Chapter 11," Yale Law Journal, 1992, 101 (5), 1043-1095.

Bris, Arturo, Ivo Welch, and Ning Zhu, "The costs of bankruptcy: Chapter 7 liquidation versus Chapter 11 reorganization," The Journal of Finance, 2006, 61 (3), 1253-1303.

Campbell, John Y., Stefano Giglio, and Parag Pathak, "Forced Sales and House Prices," American Economic Review, 2011, 101 (5), 2108-2131.

Chang, Tom and Antoinette Schoar, "Judge specific differences in chapter 11 and firm outcomes," 2013.

Dahl, Gordon B., Andreas Ravndal Kostøl, and Magne Mogstad, "Family Welfare Cultures," The Quarterly Journal of Economics, 2014, 129 (4), 1711-1752.

Davis, Steve J. and John Haltiwanger, "Gross job creation, gross job destruction and employment reallocation," The Quarterly Journal of Economics, 1992, 107 (3), 819-863.

Davydenko, Sergei A and Julian R Franks, "Do bankruptcy codes matter? A study of defaults in France, Germany, and the UK," The Journal of Finance, 2008, 63 (2), 565-608.

Djankov, Simeon, Oliver Hart, Caralee McLiesh, and Andrei Shleifer, "Debt Enforcement around the World," Journal of Political Economy, 2008, 116 (6).

Dobbie, Will and Jae Song, "Debt Relief and Debtor Outcomes: Measuring the Effects of Consumer Bankruptcy Protection," American Economic Review, 2015, 105, 1272-1311. 
Doyle Jr, Joseph J., "Child protection and child outcomes: Measuring the effects of foster care," The American Economic Review, 2007, pp. 1583-1610.

Doyle Jr., Joseph J., "Child protection and adult crime: Using investigator assignment to estimate causal effects of foster care," Journal of Political Economy, 2008, 116 (4), 746-770.

Eckbo, Espen B and Karin Thorburn, "Automatic bankruptcy auctions and fire-sales," Journal of Financial Economics, 2008, 89, 404-422.

Eisfeldt, Andrea L and Adriano A Rampini, "Capital reallocation and liquidity," Journal of Monetary Economics, 2006, 53 (3), 369-399.

Ellison, Glenn and Edward L Glaeser, "Geographic concentration in U.S. manufacturing industries: A dartboard approach," Journal of Political Economy, 1997, 105 (5), 889-927.

_ , _, and William R Kerr, "What Causes Industry Agglomeration? Evidence from Coagglomeration Patterns," American Economic Review, 2010, 100, 1195-1213.

Franks, Julian R. and Walter N. Torous, "An empirical investigation of U.S. firms in reorganization," The Journal of Finance, 1989, 44 (3), 747-770.

Galasso, Alberto and Mark Schankerman, "Patents and cumulative innovation: Causal evidence from the courts," The Quarterly Journal of Economics, 2015, 130 (1), 317-369.

Gavazza, Alessandro, "The role of trading frictions in real asset markets," The American Economic Review, 2011, 101 (4), 1106-1143.

Gertner, Robert and David Scharfstein, "A theory of workouts and the effects of reorganization law*," The Journal of Finance, 1991, 46 (4), 1189-1222.

Greenstone, Michael, Alexandre Mas, and Hoai-Luu Nguyen, "Do credit market shocks affect the real economy? Quasi-experimental evidence from the Great Recession and normal economic times," Technical Report, National Bureau of Economic Research 2014.

Grenadier, Steven R, "Local and national determinants of office vacancies," Journal of Urban Economics, 1995, 37 (1), 57-71.

_ , "The strategic exercise of options: Development cascades and overbuilding in real estate markets," The Journal of Finance, 1996, 51 (5), 1653-1679.

Hart, Oliver, "Different approaches to bankruptcy," Technical Report, National Bureau of Economic Research 2000. Working Paper 7921.

He, Zhiguo and Gregor Matvos, "Debt and creative destruction: Why could subsidizing corporate debt be optimal?," Management Science, 2015, 62 (2), 303-325.

Hotchkiss, Edith S., "Postbankruptcy performance and management turnover," The Journal of Finance, 1995, 50 (1), 3-21.

Hsieh, Chang-Tai and Peter J Klenow, "Misallocation and manufacturing TFP in China and India," The Quarterly Journal of Economics, 2009, 124 (4), 1403-1448.

Imbens, Guido W and Joshua D Angrist, "Identification and estimation of local average treatment effects," Econometrica, 1994, 62 (2), 467-476. 
Ivashina, Victoria, Benjamin C. Iverson, and David C. Smith, "The ownership and trading of debt claims in Chapter 11 restructurings," Journal of Financial Economics, Forthcoming, 2015.

Iverson, Benjamin C., "Get in line: Chapter 11 restructuring in crowded bankruptcy courts," Available at SSRN 2156045, 2015.

Jarmin, Ron S and Javier Miranda, "The longitudinal business database," Available at SSRN: http://ssrn.com/abstract=1509273, 2002.

Jensen, Michael C and William H Meckling, "Theory of the firm: Managerial behavior, agency costs and ownership structure," Journal of financial economics, 1976, 3 (4), 305-360.

Kling, Jeffrey R., "Incarceration Length, Employment, and Earnings," American Economic Review, 2006, 96 (3), 863-876.

LoPucki, Lynn $\mathbf{M}$ and William $\mathbf{C}$ Whitford, "Patterns in the bankruptcy reorganization of large publicly held companies," Cornell Law Review, 1993, 78 (4), 597-618.

Maestas, Nicole, Kathleen J Mullen, and Alexander Strand, "Does disability insurance receipt discourage work? Using examiner assignment to estimate causal effects of SSDI receipt," The American Economic Review, 2013, 103 (5), 1797-1829.

$\ldots, \ldots$, and _ , "Does disability insurance receipt discourage work? Using examiner assignment to estimate causal effects of SSDI receipt," American Economic Review, 2013, 103 (5), 1797-1829.

Maksimovic, Vojislav and Gordon Phillips, "Asset efficiency and reallocation decisions of bankrupt firms," The Journal of Finance, 1998, 53 (5), 1495-1532.

Mortensen, Dale and Randall Wright, "Competitive pricing and efficiency in search equilibrium," International Economic Review, 2002, 43 (1), 1-20.

Ottonello, Pablo, "Capital Unemployment, Financial Shocks, and Investment Slumps," 2014.

Petersen, Mitchell A and Raghuram G Rajan, "The benefits of lending relationships: Evidence from small business data," The Journal of Finance, 1994, 49 (1), 3-37.

Pulvino, Todd C, "Do asset fire sales exist? An empirical investigation of commercial aircraft transactions," The Journal of Finance, 1998, 53 (3), 939-978.

_ , "Effects of bankruptcy court protection on asset sales," Journal of Financial Economics, 1999, 52 (2), 151-186.

Ramey, Valerie A. and Matthew D. Shapiro, "Displaced capital: A study of aerospace plant closings," Journal of Political Economy, 2001, 109 (5), 958-992.

Shleifer, Andrei and Robert Vishny, "Fire Sales in Finance and Macroeconomics," Journal of Economic Perspectives, 2011, 25 (1), 29-48.

- and Robert W Vishny, "Liquidation values and debt capacity: A market equilibrium approach," The Journal of Finance, 1992, 47 (4), 1343-1366.

Staiger, Douglas and James H Stock, "Instrumental Variables Regression with Weak Instruments," Econometrica, 1997, 65 (3), 557-586. 
Strömberg, Per, "Conflicts of interest and market illiquidity in bankruptcy auctions: Theory and tests," The Journal of Finance, 2000, 55 (6), 2641-2692.

Tella, Rafael Di and Ernesto Schargrodsky, "Criminal recidivism after prison and electronic monitoring," Journal of Political Economy, 2013, 121 (1), 28-73.

Williamson, Oliver E, "Corporate finance and corporate governance," The Journal of Finance, 1988, 43 (3), 567-591. 


\section{Figure 1}

\section{Model with Bankrupt Sellers}

This numerical illustration captures the key insights from a basic search model with respect to search thresholds, asset holding time, asset utilization, average productivity of asset users for different levels of market thickness, defined in the model as markets with higher mass of assets. See Section B in the Appendix for details on the construction of the numerical illustration. Black solid lines denote regular buyers, black dotted lines are regular sellers, red dotted lines are reorganized sellers, and blue solid lines are liquidated sellers.

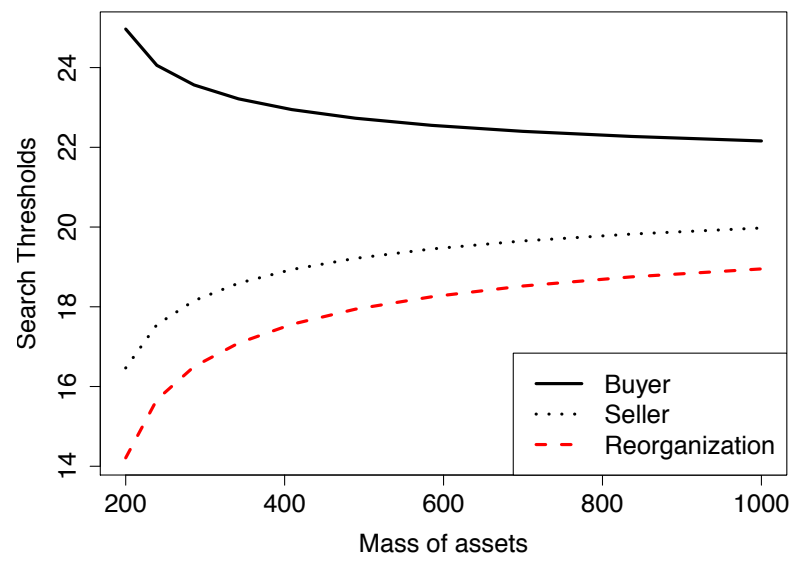

(a) Search Thresholds

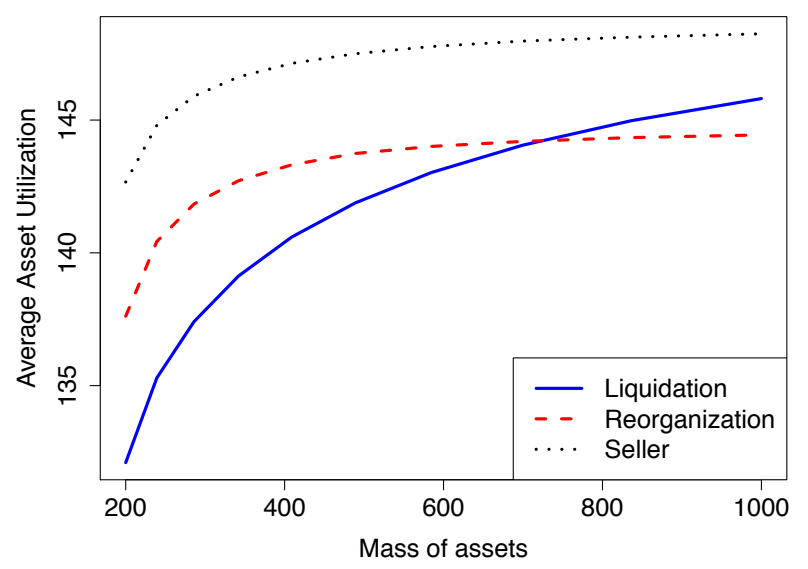

(c) Asset Utilization

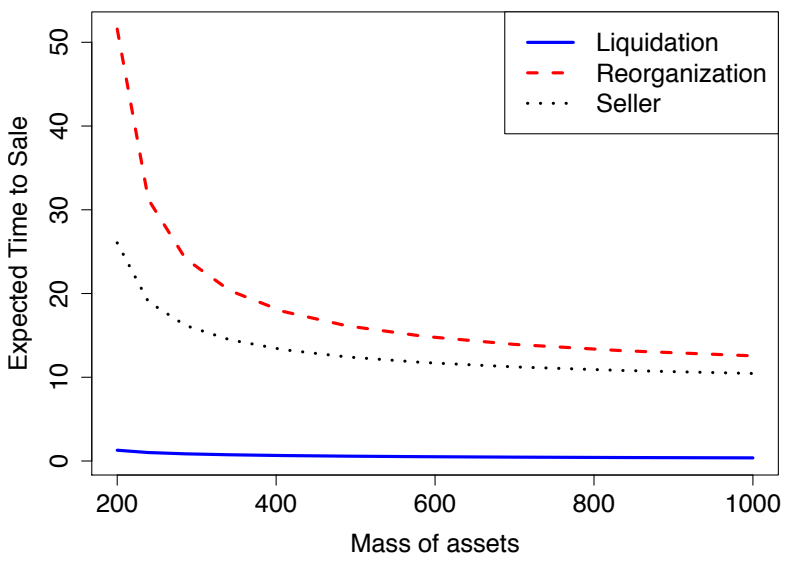

(b) Holding Time

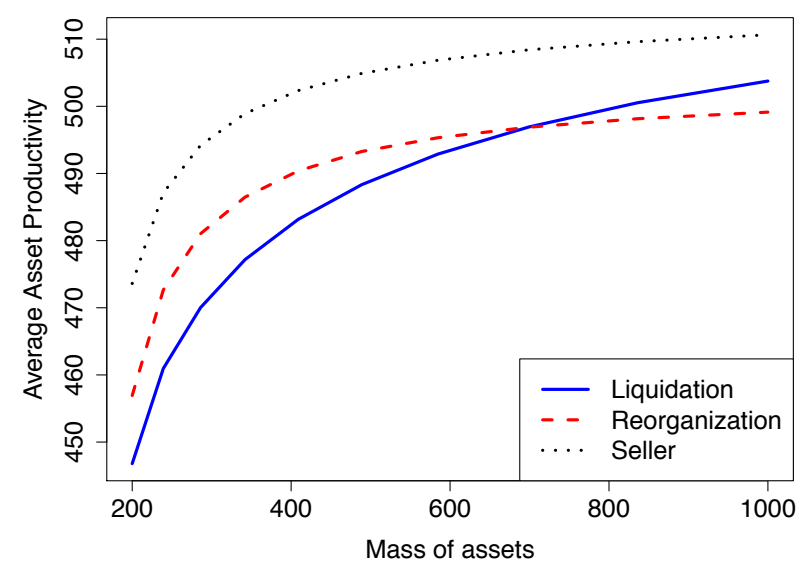

(d) Asset Productivity 


\section{Figure 2}

Agency Costs

This numerical illustration captures the key insights from a basic search model with respect to search thresholds, asset holding time, asset utilization, average productivity of asset users for different levels of market thickness, defined in the model as markets with higher mass of assets. The plots compare cases with high level of agency costs (left panel) and low level of agency costs (right panel). See Section B in the Appendix for details on the construction of the numerical illustration. Black solid lines denote regular buyers, black dotted lines are regular sellers, red dotted lines are reorganized sellers, and blue solid lines are liquidated sellers.

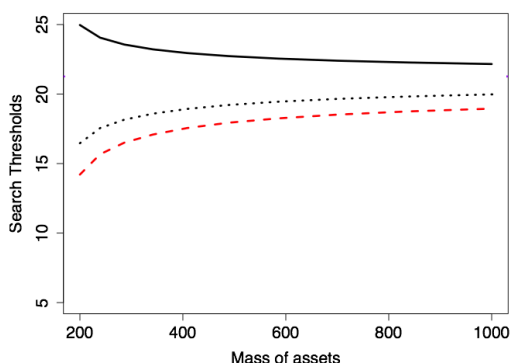

(a) Search Thresholds - Low

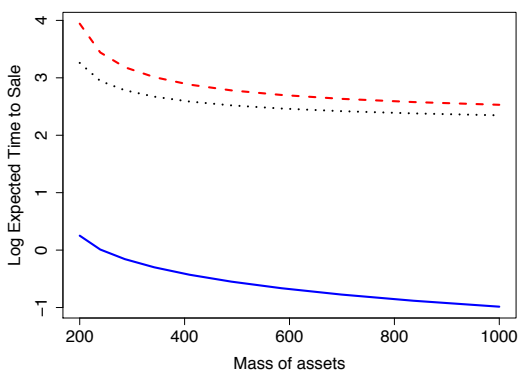

(c) Log Holding Time - Low

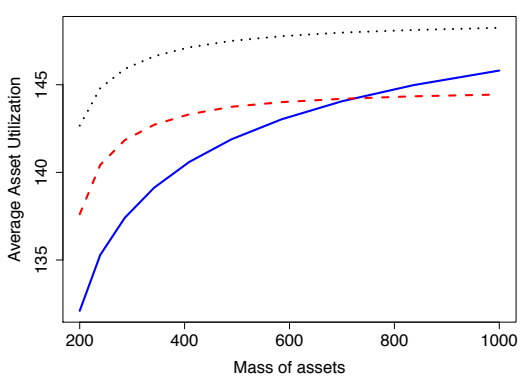

(e) Asset Utilization - Low

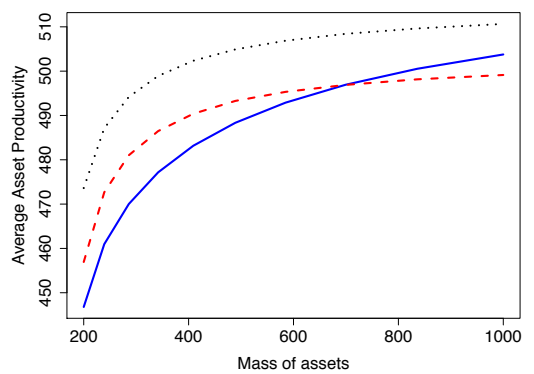

(g) Asset Productivity - Low

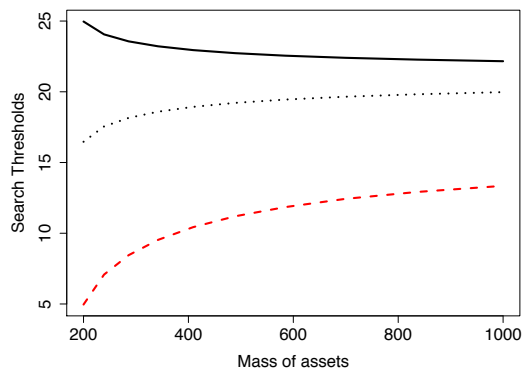

(b) Search Thresholds - High

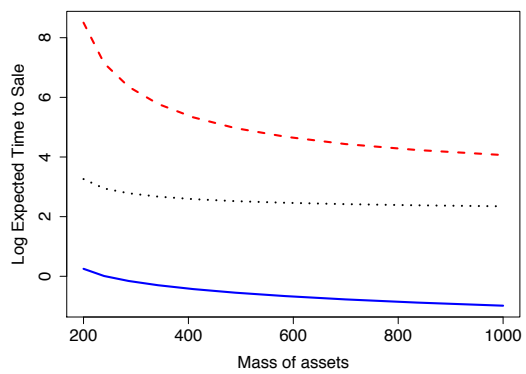

(d) Log Holding Time - High

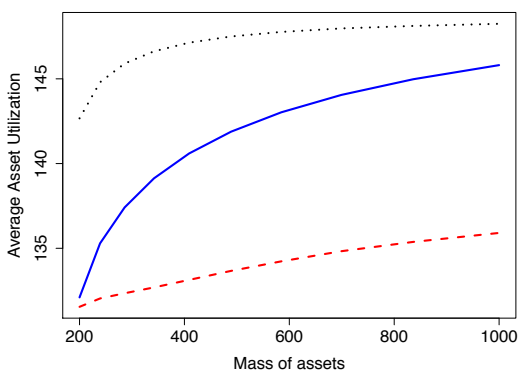

(f) Asset Utilization - High

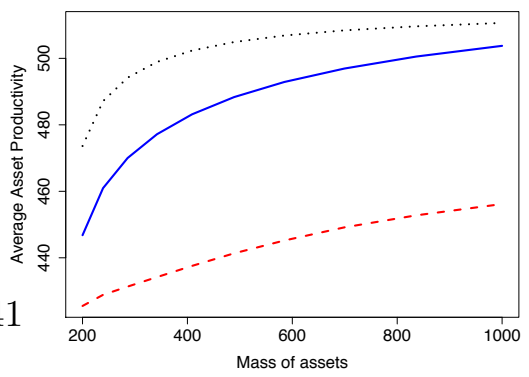

(h) Asset Productivity - High 
Figure 3

Stylized Facts About Bankruptcy Reallocation

These figures illustrate summary statistics about the reallocation process for liquidated, reorganized, and benchmark establishments. The benchmark is created from a random $5 \%$ sample of all plants in the same county as the bankrupt establishments. Panel A shows the percentage of plants that continue to be operated by the original firms in the 5 years following the bankruptcy filing. Panel $\mathrm{B}$ plots the share of establishments that are occupied regardless of the owner, thereby taking into account reallocation to new users. Panel $\mathrm{C}$ is similar to Panel B, but instead shows total employment as a percentage of employment in year 0 .

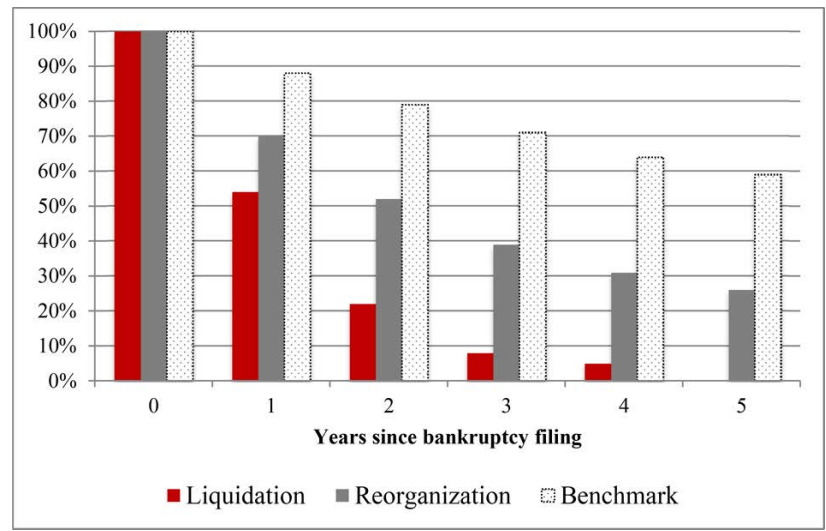

(a) Plant Continuation Probability Over Time

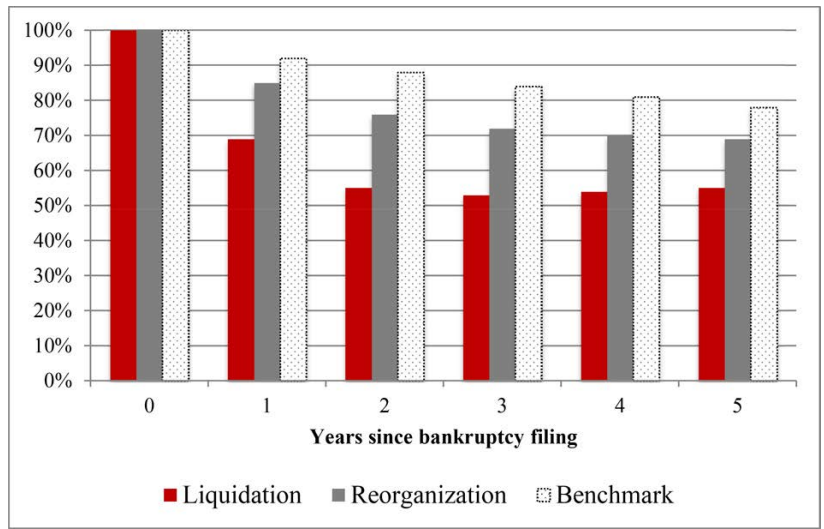

(b) Plant Occupancy Rate Over Time

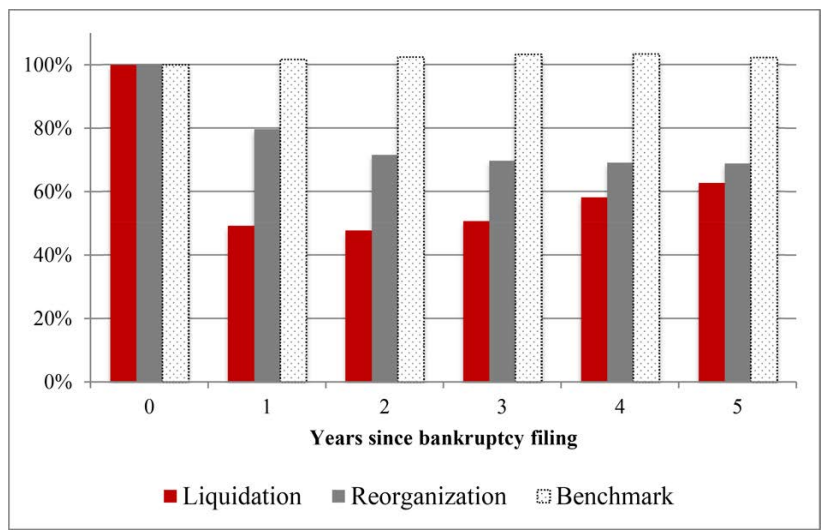

(c) Plant Employment Over Time 
Figure 4

Non-Parametric First Stage

This figure plots the relationship between the probability of case conversion and our preferred instrument, the share of all other Chapter 11 cases that a judge has converted to Chapter 7, using a non-parametric kernel regression. To be consistent with the regression analysis in the paper, we first residualize the probability of case conversion to all control variables in Table 3, including division-year fixed effects. Gray area represents the $95 \%$ confidence interval. For disclosure reasons, we truncate the $5 \%$ tails of the distribution.

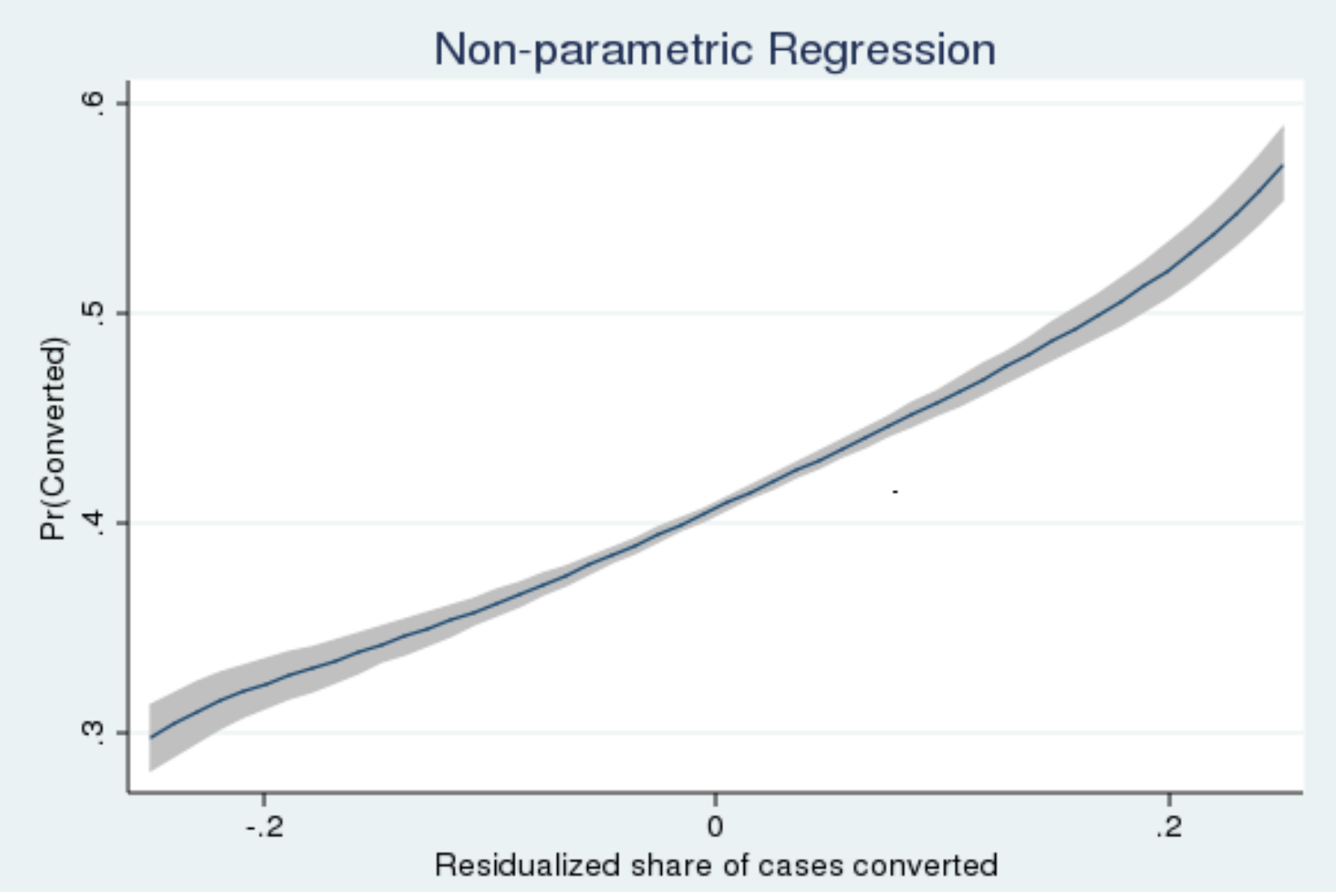




\section{Figure 5}

Reduced Form Dynamics

This figure displays coefficient estimates of the effect of judge instrument on occupancy rates (left column) and average employment (right column) both before and after bankrutpcy. In Panels (a) and (b), coefficient estimates $\beta$ are from reduced-form regressions $Y_{p, i, t+k}=\alpha+\beta \cdot \phi_{j}+\gamma X_{p, i, t}+\delta_{d, t}+$ $\mu_{k}+\epsilon_{p, i, t+k}$, where $\phi_{j}$ is judge leniency instrument, and specifications contain the full set of control variables in Column 3 of Table 3, including division-by-year fixed effects. In the remaining panels, coefficient estimates displayed are $\beta_{L}$ and $\beta_{H}$, which are derived from reduced-form regressions $Y_{p, i, t+k}=\alpha+\beta_{L} \cdot \phi_{j} \cdot \operatorname{Low}_{p, t}+\beta_{H} \cdot \phi_{j} \cdot H i g h_{p, t}+\gamma X_{p, i, t}+\delta_{d, t}+\mu_{k}+\epsilon_{p, i, t+k}$, where the instrument $\phi_{j}$ is interacted with dummy variables $L_{o w}, t$ and $H_{i g h}, t$, which indicate if a plant resides in a county with low or high market thickness (Panels (c) and (d)) or access to finance (Panels (e) and (f)). All control variables and fixed effects are also interacted with $L o w_{p, t}$ to allow for flexible estimates across market types. Standard-error bars, based on clustering at the division-year level, are also displayed.

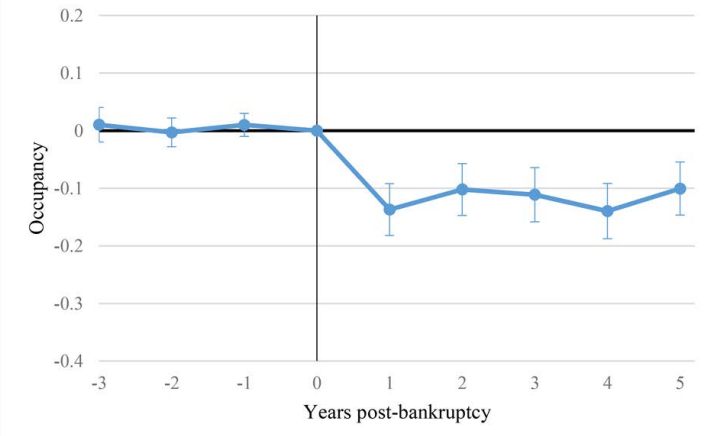

(a) Occupied-Main Effect

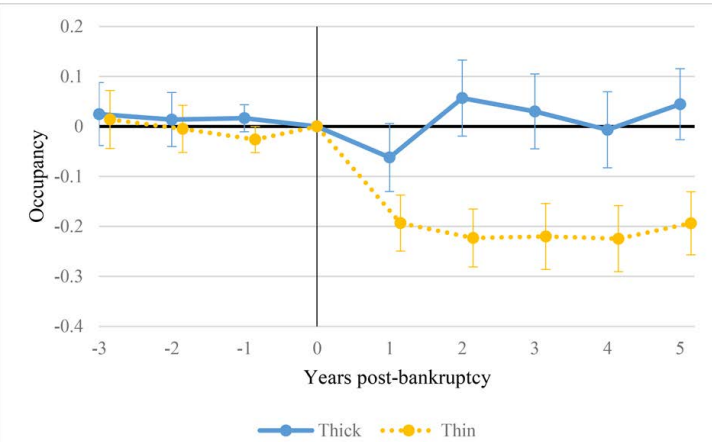

(c) Occupied-By Market Thickness

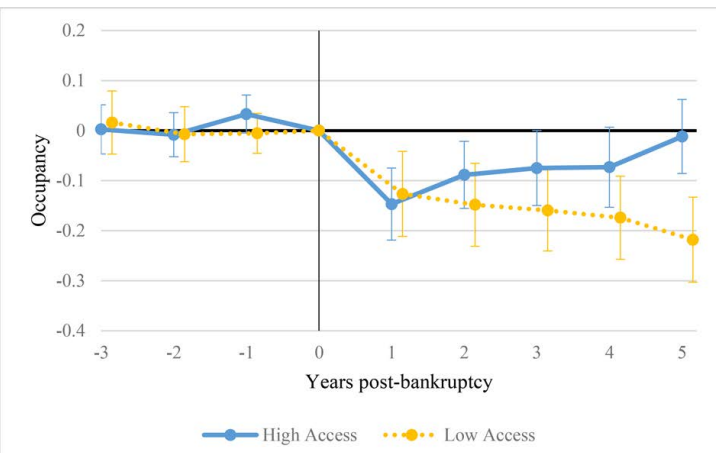

(e) Occupied-By Access to Capital

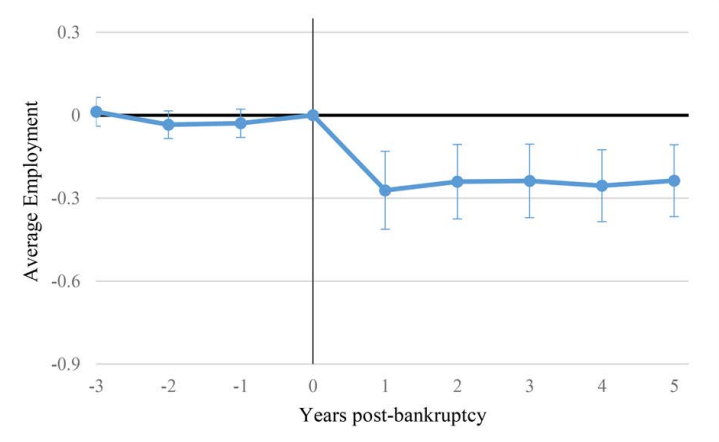

(b) Employment-Main Effect

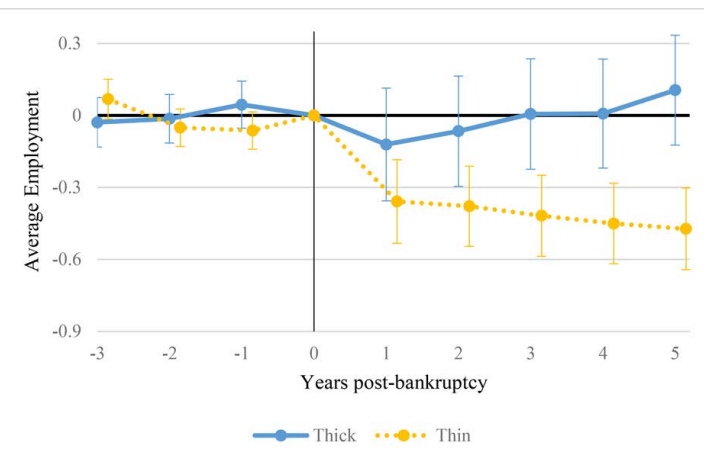

(d) Employment-By Market Thickness

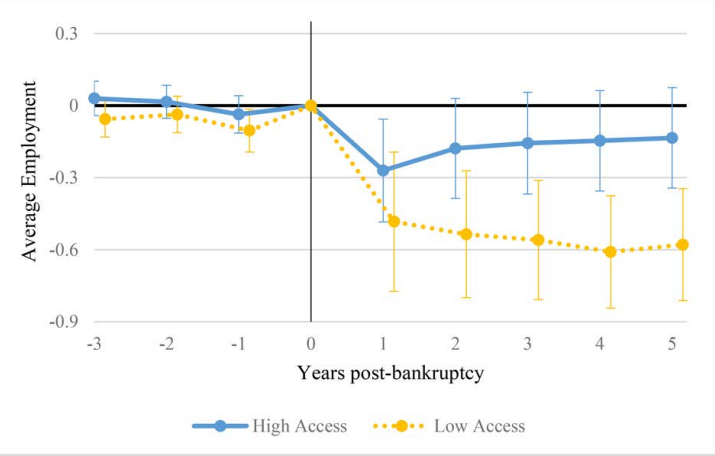

(f) Employment-By Access to Capital 


\section{Table 1}

\section{Sample Summary Statistics}

Panel A of this table presents summary statistics on the plants and firms in our final sample, both overall and split by firms that are reorganized in Chapter 11 and those that are liquidated in Chapter 7. Observation counts are rounded to the nearest thousand due to disclosure requirements of the U.S. Census. All numbers shown are averages, except for observation counts. Payroll and payroll per employee are in thousands of nominal U.S. dollars. Market thickness and Share of small business loans are defined in the text. Share of small business loans is only available beginning in 1996, leaving a total of 99,000 plants for these summary stats. Panel B shows the industry distribution in our sample and the percent of firms liquidated in each industry. Panel $\mathrm{C}$ describes the characteristics of the firms replacing the dead bankrupt plants, distinguishing between new firms, existing firms that already had an establishment in the same county, and other existing firms. In Panel $\mathrm{C}$ we also report the percentages of reallocations to the same 2- and 3-digit NAICS industry.

\section{Panel A: Summary Statistics}

\begin{tabular}{lrrr}
\hline & All & Reorganized & Liquidated \\
\hline Plant-level characteristics & & & \\
Employment & 35.9 & 38.0 & 26.9 \\
Total plants & 129,000 & 105,000 & 24,000 \\
Firm-level characteristics & & & \\
No. Plants & 4.7 & 6.5 & 2.2 \\
Employment & 169.0 & 245.4 & 57.9 \\
Payroll (000s) & $4,507.7$ & $6,819.0$ & $1,146.3$ \\
Payroll/Employee (000s) & 23.7 & 26.0 & 20.2 \\
Age & 9.9 & 10.7 & 8.9 \\
Number of firms & 28,000 & 17,000 & 11,000 \\
County-level characteristics & & & \\
Market thickness & $6.4 \%$ & $6.4 \%$ & $6.4 \%$ \\
Share of small business loans & $43.8 \%$ & $43.7 \%$ & $43.9 \%$ \\
\hline
\end{tabular}

Panel B: Industry Distribution

\begin{tabular}{lrrr}
\hline & Total Plants & Total Firms & \% Liquidated \\
\hline Agriculture, Mining, and Construction & 4,000 & 3,500 & 45 \\
Manufacturing & 7,000 & 4,500 & 38 \\
Transportation, Utilities \& Warehousing & 7,000 & 3,000 & 43 \\
Wholesale \& Retail Trade & 62,000 & 6,500 & 44 \\
Services & 18,000 & 5,500 & 37 \\
Accommodation, Food, and Entertainment & 16,000 & 4,000 & 44 \\
Other & 15,000 & 3,500 & 32 \\
\hline
\end{tabular}

Panel C: New Entrant Characteristics

\begin{tabular}{lrrrrrr}
\hline & \multicolumn{2}{c}{ All } & \multicolumn{2}{c}{ Reorganized } & \multicolumn{2}{c}{ Liquidated } \\
\hline Local vs. non-local & & & & & & \\
New entrant & 32,500 & $52.0 \%$ & 23,500 & $48.0 \%$ & 9,500 & $70.4 \%$ \\
Local entrant, existing & 21,500 & $34.4 \%$ & 18,000 & $36.7 \%$ & 3,000 & $22.2 \%$ \\
Non-local entrant, existing & 8,500 & $13.6 \%$ & 7,500 & $15.3 \%$ & 1,000 & $7.4 \%$ \\
\hline Total & 62,500 & $100.0 \%$ & 49,000 & $100.0 \%$ & 13,500 & $100.0 \%$ \\
\hline Industry transitions & & & & & & \\
In same 3-digit NAICS & 29,000 & $46.4 \%$ & 24,000 & $49.0 \%$ & 5,000 & $37.0 \%$ \\
In same 2-digit NAICS & 34,500 & $55.2 \%$ & 28,500 & $58.2 \%$ & 6,000 & $44.4 \%$ \\
\hline
\end{tabular}




\section{Table 2}

\section{Reallocation Determinants}

This table shows results from a regression of a dummy for whether a plant is replaced within 5 years from bankruptcy filing (conditional on death of original plant) on a set of county and industry (2-digit NAICS) characteristics computed at the year of filing. All county-level and industry-level controls are dummy variables equal to 1 if the county is above-median in the given category. Plant- and firm-level controls identical to those in Table 3 are also included, but are not reported for brevity. In addition, with the exception of column 4, we include fixed effects for the filing year, as well as for the number of years after plant death in which we looked for a replacement (up to 5 years after filing). The sample includes all establishments that died within 5 years of filing. Standard errors, clustered at the division by year level, are shown in parentheses. $*, * *$, and ${ }^{* * *}$ denote statistical significance at the $10 \%, 5 \%$, and $1 \%$ level, respectively.

\begin{tabular}{|c|c|c|c|c|c|c|}
\hline \multirow[t]{2}{*}{ Dependent variable: } & \multicolumn{6}{|c|}{ Plant reallocation dummy } \\
\hline & $(1)$ & $(2)$ & $(3)$ & $(4)$ & $(5)$ & $(6)$ \\
\hline \\
\hline $\begin{array}{l}\text { Local Economic Conditions } \\
\text { No. plants above median }\end{array}$ & $\begin{array}{l}0.029^{* * *} \\
(0.005)\end{array}$ & & & $\begin{array}{c}0.034^{* * *} \\
(0.007)\end{array}$ & $\begin{array}{l}0.029^{* * *} \\
(0.005)\end{array}$ & $\begin{array}{l}0.028^{* * *} \\
(0.005)\end{array}$ \\
\hline 3-year employment growth above median & $\begin{array}{l}0.019^{* * *} \\
(0.004)\end{array}$ & & & $\begin{array}{c}0.027^{* * *} * \\
(0.005)\end{array}$ & $\begin{array}{l}0.019^{* * *} \\
(0.004)\end{array}$ & $\begin{array}{l}0.018^{* * *} \\
(0.004)\end{array}$ \\
\hline Payroll per employee above median & $\begin{array}{l}0.032^{* * *} \\
(0.006)\end{array}$ & & & $\begin{array}{c}0.004 \\
(0.009)\end{array}$ & $\begin{array}{l}0.032^{* * *} \\
(0.007)\end{array}$ & $\begin{array}{l}0.029 * * * \\
(0.006)\end{array}$ \\
\hline \multicolumn{7}{|l|}{ Industry Economic Conditions } \\
\hline No. plants above median & & $\begin{array}{l}-0.012 \\
(0.008)\end{array}$ & $\begin{array}{r}-0.017^{*} \\
(0.009)\end{array}$ & $\begin{array}{r}-0.035^{*} \\
(0.019)\end{array}$ & $\begin{array}{l}-0.016^{*} \\
(0.009)\end{array}$ & $\begin{array}{l}0.025 \\
(0.021)\end{array}$ \\
\hline 3-year employment growth above median & & $\begin{array}{l}0.026^{* * *} \\
(0.007)\end{array}$ & $\begin{array}{l}0.005 \\
(0.009)\end{array}$ & $\begin{array}{l}0.026^{*} \\
(0.015)\end{array}$ & $\begin{array}{l}0.006 \\
(0.009)\end{array}$ & $\begin{array}{l}-0.004 \\
(0.009)\end{array}$ \\
\hline Payroll per employee above median & & $\begin{array}{l}0.006 \\
(0.009)\end{array}$ & $\begin{array}{l}0.011 \\
(0.010)\end{array}$ & $\begin{array}{l}-0.011 \\
(0.019)\end{array}$ & $\begin{array}{l}0.011 \\
(0.009)\end{array}$ & $\begin{array}{l}-0.000 \\
(0.014)\end{array}$ \\
\hline \multicolumn{7}{|c|}{$\begin{array}{l}\text { Industry Fixed Effects } \\
\text { (Omitted: Agriculture, Mining, and Construction) }\end{array}$} \\
\hline Manufacturing & $\begin{array}{l}0.037^{* * *} \\
(0.013)\end{array}$ & & $\begin{array}{l}0.025^{*} \\
(0.015)\end{array}$ & $\begin{array}{c}0.020 \\
(0.024)\end{array}$ & $\begin{array}{l}0.028^{*} \\
(0.015)\end{array}$ & \\
\hline Transportation, Utilities \& Warehousing & $\begin{array}{l}0.005 \\
(0.018)\end{array}$ & & $\begin{array}{l}-0.006 \\
(0.020)\end{array}$ & $\begin{array}{r}-0.051^{*} \\
(0.029)\end{array}$ & $\begin{array}{l}-0.008 \\
(0.019)\end{array}$ & \\
\hline Wholesale \& Retail Trade & $\begin{array}{l}0.080^{* * *} \\
(0.013)\end{array}$ & & $\begin{array}{l}0.087^{* * *} \\
(0.014)\end{array}$ & $\begin{array}{c}0.042^{* *} \\
(0.021)\end{array}$ & $\begin{array}{l}0.082^{* * *} \\
(0.014)\end{array}$ & \\
\hline Services & $\begin{array}{l}0.091^{* * *} \\
(0.014)\end{array}$ & & $\begin{array}{l}0.096^{* * *} \\
(0.014)\end{array}$ & $\begin{array}{c}0.083^{* * *} \\
(0.022)\end{array}$ & $\begin{array}{l}0.086^{* * *} \\
(0.014)\end{array}$ & \\
\hline Accommodation, Food, and Entertainment & $\begin{array}{l}0.087^{* * *} \\
(0.015)\end{array}$ & & $\begin{array}{l}0.087^{* * *} \\
(0.019)\end{array}$ & $\begin{array}{c}0.060^{*} \\
(0.035)\end{array}$ & $\begin{array}{l}0.082^{* * *} \\
(0.018)\end{array}$ & \\
\hline Other & $\begin{array}{l}0.146^{* * *} \\
(0.016)\end{array}$ & & $\begin{array}{l}0.144^{* * *} \\
(0.018)\end{array}$ & $\begin{array}{c}0.143^{* * *} \\
(0.022)\end{array}$ & $\begin{array}{l}0.138^{* * *} \\
(0.017)\end{array}$ & \\
\hline Plant and firm controls & Yes & Yes & Yes & Yes & Yes & Yes \\
\hline 2-digit NAICS FE & No & No & No & No & No & Yes \\
\hline Filing year FE & Yes & Yes & Yes & No & Yes & Yes \\
\hline \# of years searched FE & Yes & Yes & Yes & No & Yes & Yes \\
\hline Observations & 101,000 & 101,000 & 101,000 & 101000 & 101,000 & 101,000 \\
\hline Adj. R-squared & 0.0952 & 0.0872 & 0.0921 & 0.0295 & 0.0955 & 0.0984 \\
\hline
\end{tabular}




\section{Table 3}

First Stage

This table reports first stage results. The dependent variable is a dummy equal to one if a case is converted from Chapter 11 reorganization to Chapter 7 liquidation. Column 1 reports results at the level of the bankruptcy filing, while Columns 2 and 3 report results at the level of the plant. In this and all other regression tables, each observation is weighted by the inverse of the total number of plants belonging to the bankruptcy filing so as to give equal weight to each bankruptcy filing. The instrument we use is defined as the share of all other Chapter 11 cases that a judge converted to Chapter 7. The sample includes all firms that filed for Chapter 11 bankruptcy between 1992 and 2005. Part of a group filing is an indicator variable equal to one if other related firms (e.g. subsidiaries of the same firm) also filed for bankruptcy at the same time. Other controls are self-explanatory. All specifications contain 24 industry fixed effects and 2,361 bankruptcy-division-by-year fixed effects. Standard errors, clustered at the division-by-year level, are shown in parentheses. ${ }^{*}, * *$, and ${ }^{* * *}$ denote statistical significance at the $10 \%, 5 \%$, and $1 \%$ level, respectively.

\begin{tabular}{llll}
\hline Dependent variable: & \multicolumn{3}{c}{ Converted to Liquidation } \\
& $(1)$ & $(2)$ & $(3)$ \\
\hline Share of other cases converted & $0.581^{* * *}$ & $0.581^{* * *}$ & $0.580^{* * *}$ \\
& $(0.056)$ & $(0.054)$ & $(0.054)$ \\
Ln(employees at plant) & & & $0.016^{* * *}$ \\
& & & $(0.003)$ \\
Plant age (years) & & & $-0.005^{* * *}$ \\
& $-0.023^{* * *}$ & $-0.022^{* * *}$ & $(0.000)$ \\
Ln(tot. employees at firm) & $(0.003)$ & $(0.002)$ & $(0.004)$ \\
& $-0.038^{* * *}$ & $-0.039^{* * *}$ & $-0.022^{* * *}$ \\
Ln(no. of plants at firm) & $(0.006)$ & $(0.005)$ & $(0.006)$ \\
& $-0.086^{* * *}$ & $-0.085^{* * *}$ & $-0.086^{* * *}$ \\
Part of a group filing & $(0.011)$ & $(0.011)$ & $(0.011)$ \\
& Bankruptcy & Plant & Plant \\
& Yes & Yes & Yes \\
Unit of Observation & Yes & Yes & Yes \\
2-digit NAICS Fixed Effects & 28,000 & 129,000 & 129,000 \\
Division-year Fixed Effects & 0.102 & 0.165 & 0.170 \\
Observations & 107.2 & 114.9 & 113.5 \\
Adj. R-squared & & & \\
F-stat for instrument & & & \\
\hline
\end{tabular}




\section{Table 4}

First Stage Heterogeneity

This table reports first stage results for subsamples of the data by size and market characteristics. The first column shows the number of establishments in the group, and the second column shows the number of firms. Column 3 shows the percentage of firms in the subsample that are converted to Chapter 7. Column 4 shows the coefficient on the instrument share converted when the first stage is run only on that subsample, with *** denoting statistical significance at the $1 \%$ level. These regressions include all control variables and fixed effects as in column 3 of Table 3 . As discussed in the text, these coefficients can also be interpreted as the share of firms that are sensitive to the instrument. In column 5 we display the $F$-stat for the first stage. Finally, column 6 shows the estimated percentage of firms in the group that would always be converted regardless of the judge.

\begin{tabular}{lllllll}
\hline & Observations & $\begin{array}{l}\text { \# of firms } \\
(1)\end{array}$ & $\begin{array}{l}\text { Percent } \\
\text { Liquidated } \\
(3)\end{array}$ & $\begin{array}{l}\text { Coefficient on } \\
\text { share converted } \\
(4)\end{array}$ & $\begin{array}{l}\text { F-stat } \\
(5)\end{array}$ & $\begin{array}{l}\text { Fraction of } \\
\text { always takers } \\
(6)\end{array}$ \\
\hline Full Sample & 129,000 & 28,000 & 41 & $0.581^{* * *}$ & 114.10 & 18 \\
& & & & & & \\
Employees in firm: & & & & & & \\
$0-5$ & 8,000 & 7,000 & 44 & $0.492^{* * *}$ & 19.51 & 25 \\
$6-25$ & 11,000 & 10,500 & 44 & $0.559^{* * *}$ & 33.59 & 21 \\
$26-100$ & 11,000 & 6,500 & 41 & $0.880^{* * *}$ & 66.87 & 6 \\
$101-1000$ & 22,000 & 3,000 & 29 & $0.521^{* * *}$ & 8.74 & 9 \\
$>1000$ & 77,000 & 1,000 & 13 & 0.262 & 1.34 & 5 \\
& & & & & & \\
Market Characteristics: & & & & & & \\
Thick markets & 64,000 & 12,500 & 41 & $0.557^{* * *}$ & 41.93 & 19 \\
Thin markets & 65,000 & 17,000 & 40 & $0.603^{* * *}$ & 77.11 & 16 \\
High access to capital & 50,000 & 12,000 & 40 & $0.664^{* * *}$ & 56.65 & 14 \\
Low access to capital & 49,000 & 9,500 & 43 & $0.484^{* * *}$ & 24.23 & 23 \\
\hline
\end{tabular}




\section{Table 5}

Random Judge Assignment

This table reports randomization tests to illustrate the random assignment of judges to bankruptcy filings within a division. The dependent variable is the share of Chapter 11 cases that a judge ever converted to Chapter 7, which we use as an instrumental variable. All the regressions are at the plant level. Column 1 contains only division-by-year fixed effects as controls and is included to demonstrate that the $R^{2}$ is not affected by the inclusion of any controls in Columns $2-8$. Plant-level controls include employment at the location in the 3 years prior to bankruptcy, in addition to the standard controls as in Table 3. Heterogeneity measures are as defined in the text, and other independent variables are self-explanatory. The sample includes all firms that filed for Chapter 11 bankruptcy between 1992 and 2005. Standard errors, clustered at the division-by-year level, are shown in parentheses. ${ }^{*},{ }^{* *}$, and ${ }^{* * *}$ denote statistical significance at the $10 \%, 5 \%$, and $1 \%$ level, respectively.

\begin{tabular}{|c|c|c|c|c|c|c|c|c|}
\hline \multirow[t]{2}{*}{ Dependent variable: } & \multicolumn{8}{|c|}{ Share converted } \\
\hline & $(1)$ & $(2)$ & $(3)$ & $(4)$ & $(5)$ & $(6)$ & $(7)$ & $(8)$ \\
\hline \multicolumn{9}{|l|}{ Plant- and firm-level controls: } \\
\hline $\operatorname{Ln}(\text { employees at plant })_{0}$ & & $\begin{array}{l}0.0002 \\
(0.001)\end{array}$ & $\begin{array}{c}-0.0001 \\
(0.001)\end{array}$ & $\begin{array}{c}-0.0001 \\
(0.001)\end{array}$ & $\begin{array}{c}-0.0001 \\
(0.001)\end{array}$ & $\begin{array}{c}-0.0001 \\
(0.001)\end{array}$ & $\begin{array}{c}-0.0001 \\
(0.001)\end{array}$ & $\begin{array}{r}-0.0001 \\
(0.001)\end{array}$ \\
\hline $\operatorname{Ln}(\text { employees at plant })_{-1}$ & & & $\begin{array}{l}0.0004 \\
(0.000)\end{array}$ & $\begin{array}{l}0.0004 \\
(0.000)\end{array}$ & $\begin{array}{l}0.0004 \\
(0.000)\end{array}$ & $\begin{array}{l}0.0004 \\
(0.000)\end{array}$ & $\begin{array}{l}0.0004 \\
(0.000)\end{array}$ & $\begin{array}{l}0.0004 \\
(0.000)\end{array}$ \\
\hline $\operatorname{Ln}(\text { employees at plant })_{-2}$ & & & $\begin{array}{l}-0.0000 \\
(0.000)\end{array}$ & $\begin{array}{l}-0.0000 \\
(0.000)\end{array}$ & $\begin{array}{l}-0.0000 \\
(0.000)\end{array}$ & $\begin{array}{l}-0.0000 \\
(0.000)\end{array}$ & $\begin{array}{l}-0.0000 \\
(0.000)\end{array}$ & $\begin{array}{l}-0.0000 \\
(0.000)\end{array}$ \\
\hline $\operatorname{Ln}(\text { employees at plant })_{-3}$ & & & $\begin{array}{l}0.0003 \\
(0.000)\end{array}$ & $\begin{array}{l}0.0003 \\
(0.000)\end{array}$ & $\begin{array}{l}0.0003 \\
(0.000)\end{array}$ & $\begin{array}{l}0.0003 \\
(0.000)\end{array}$ & $\begin{array}{l}0.0003 \\
(0.000)\end{array}$ & $\begin{array}{l}0.0003 \\
(0.000)\end{array}$ \\
\hline Plant age (years) & & $\begin{array}{c}-0.0000 \\
(0.000)\end{array}$ & $\begin{array}{c}-0.0001 \\
(0.000)\end{array}$ & $\begin{array}{c}-0.0001 \\
(0.000)\end{array}$ & $\begin{array}{c}-0.0001 \\
(0.000)\end{array}$ & $\begin{array}{c}-0.0001 \\
(0.000)\end{array}$ & $\begin{array}{r}-0.0001 \\
(0.000)\end{array}$ & $\begin{array}{l}-0.0001 \\
(0.000)\end{array}$ \\
\hline $\operatorname{Ln}$ (tot. employees at firm) & & $\begin{array}{l}0.0009 \\
(0.001)\end{array}$ & $\begin{array}{l}0.0010 \\
(0.001)\end{array}$ & $\begin{array}{l}0.0010 \\
(0.001)\end{array}$ & $\begin{array}{l}0.0010 \\
(0.001)\end{array}$ & $\begin{array}{l}0.0009 \\
(0.001)\end{array}$ & $\begin{array}{l}0.0009 \\
(0.001)\end{array}$ & $\begin{array}{l}0.0010 \\
(0.001)\end{array}$ \\
\hline $\operatorname{Ln}($ no. plants at firm) & & $\begin{array}{c}-0.0012 \\
(0.001)\end{array}$ & $\begin{array}{c}-0.0012 \\
(0.001)\end{array}$ & $\begin{array}{r}-0.0012 \\
(0.001)\end{array}$ & $\begin{array}{l}-0.0012 \\
(0.001)\end{array}$ & $\begin{array}{c}-0.0012 \\
(0.001)\end{array}$ & $\begin{array}{c}-0.0012 \\
(0.001)\end{array}$ & $\begin{array}{l}-0.0012 \\
(0.001)\end{array}$ \\
\hline Part of a group filing & & $\begin{array}{l}0.0014 \\
(0.002)\end{array}$ & $\begin{array}{l}0.0014 \\
(0.002)\end{array}$ & $\begin{array}{l}0.0014 \\
(0.002)\end{array}$ & $\begin{array}{l}0.0014 \\
(0.002)\end{array}$ & $\begin{array}{l}0.0014 \\
(0.002)\end{array}$ & $\begin{array}{l}0.0014 \\
(0.002)\end{array}$ & $\begin{array}{l}0.0014 \\
(0.002)\end{array}$ \\
\hline \multicolumn{9}{|l|}{$\begin{array}{l}\text { Dummy }=\mathbf{1} \text { if above median: } \\
\text { Heterogeneity measures: }\end{array}$} \\
\hline Market Thickness & & & & $\begin{array}{l}0.0001 \\
(0.001)\end{array}$ & & & $\begin{array}{l}0.0000 \\
(0.001)\end{array}$ & $\begin{array}{l}0.0000 \\
(0.001)\end{array}$ \\
\hline Share of small business loans & & & & & $\begin{array}{l}0.0007 \\
(0.001)\end{array}$ & & $\begin{array}{l}0.0006 \\
(0.001)\end{array}$ & $\begin{array}{l}0.0007 \\
(0.001)\end{array}$ \\
\hline 3-year employment growth in county & & & & & & $\begin{array}{l}0.0017 \\
(0.001)\end{array}$ & $\begin{array}{l}0.0017 \\
(0.001)\end{array}$ & $\begin{array}{l}0.0016 \\
(0.001)\end{array}$ \\
\hline \multicolumn{9}{|l|}{ Other economic conditions: } \\
\hline No. of plants in county & & & & & & & & $\begin{array}{r}-0.0006 \\
(0.001)\end{array}$ \\
\hline Payroll per employee in county & & & & & & & & $\begin{array}{l}0.0012 \\
(0.001)\end{array}$ \\
\hline No. of plants in industry & & & & & & & & $\begin{array}{l}0.0061 \\
(0.004)\end{array}$ \\
\hline Payroll per employee in industry & & & & & & & & $\begin{array}{l}0.0006 \\
(0.002)\end{array}$ \\
\hline 3-year employment growth in industry & & & & & & & & $\begin{array}{l}-0.0015 \\
(0.001)\end{array}$ \\
\hline 2-digit NAICS fixed effects & No & Yes & Yes & Yes & Yes & Yes & Yes & Yes \\
\hline Division-year fixed effects & Yes & Yes & Yes & Yes & Yes & Yes & Yes & Yes \\
\hline F-stat for joint significance of industry FE & & 0.791 & 0.786 & 0.791 & 0.791 & 0.785 & 0.794 & 0.766 \\
\hline Observations & 129,000 & 129,000 & 129,000 & 129,000 & 129,000 & 129,000 & 129,000 & 129,000 \\
\hline Adj. R-squared & 0.777 & 0.777 & 0.777 & 0.777 & 0.777 & 0.778 & 0.778 & 0.778 \\
\hline
\end{tabular}




\section{Table 6}

\section{Liquidation and Plant Outcomes}

This table reports regression results showing the effect of liquidation on four plant outcomes 5 years after the bankruptcy filing. Continues is an indicator equal to 1 if the plant has at least one employee and is still owned by the original bankrupt firm 5 years after the bankruptcy filing. Holding Time is the number of years after bankruptcy (from 0 to 5) until a plant is not occupied by the original bankrupt firm. Occupied is an indicator equal to 1 if the plant has at least one employee regardless of the occupant. Average employment is the mean number of employees at the plant over the five years after the bankruptcy filing (similar results for payrolls are presented in the appendix). For all four dependent variables we display regular OLS and 2SLS estimates. All specifications contain the full set of control variables in Column 3 of Table 3, including division-by-year and industry fixed effects. Standard errors, clustered at the division-by-year level, are shown in parentheses. $*, * *$, and ${ }^{* * *}$ denote statistical significance at the $10 \%, 5 \%$, and $1 \%$ level, respectively.

\begin{tabular}{|c|c|c|c|c|c|c|c|c|}
\hline \multirow{2}{*}{$\begin{array}{l}\text { Dependent variable: } \\
\text { Model: }\end{array}$} & \multicolumn{2}{|c|}{ Continues } & \multicolumn{2}{|c|}{ Holding Time } & \multicolumn{2}{|c|}{ Occupied } & \multicolumn{2}{|c|}{ Ln(Avg. Employment) } \\
\hline & $\begin{array}{l}\text { OLS } \\
(1)\end{array}$ & $\begin{array}{l}\text { IV-2SLS } \\
(2)\end{array}$ & $\begin{array}{l}\text { OLS } \\
(3)\end{array}$ & $\begin{array}{l}\text { IV-2SLS } \\
(4)\end{array}$ & $\begin{array}{l}\text { OLS } \\
(5)\end{array}$ & $\begin{array}{l}\text { IV-2SLS } \\
(6)\end{array}$ & $\begin{array}{l}\text { OLS } \\
(7)\end{array}$ & $\begin{array}{l}\text { IV-2SLS } \\
(8)\end{array}$ \\
\hline Liquidation & $\begin{array}{l}-0.300^{* * *} \\
(0.005)\end{array}$ & $\begin{array}{l}-0.324^{* * *} \\
(0.061)\end{array}$ & $\begin{array}{c}-1.773^{* * *} \\
(0.024)\end{array}$ & $\begin{array}{c}-1.657^{* * *} \\
(0.297)\end{array}$ & $\begin{array}{l}-0.156^{* * *} \\
(0.007)\end{array}$ & $\begin{array}{l}-0.174^{* *} \\
(0.079)\end{array}$ & $\begin{array}{l}-0.565^{* * *} \\
(0.019)\end{array}$ & $\begin{array}{l}-0.416^{*} \\
(0.217)\end{array}$ \\
\hline Control Variables & Yes & Yes & Yes & Yes & Yes & Yes & Yes & Yes \\
\hline Div x Year FE & Yes & Yes & Yes & Yes & Yes & Yes & Yes & Yes \\
\hline Observations & 129,000 & 129,000 & 129,000 & 129,000 & 129,000 & 129,000 & 129,000 & 129,000 \\
\hline Adjusted R-squared & 0.230 & 0.152 & 0.288 & 0.211 & 0.130 & 0.039 & 0.295 & 0.214 \\
\hline
\end{tabular}




\section{Table 7}

\section{Heterogeneous Effects on Utilization - Market Thickness}

This table shows how the effects of liquidation vary depending on the thickness of the local asset market. Using our measure of market thickness (defined in the text), we divide the sample into plants in thick counties (above-median) or thin counties (below-median). We then present, in columns 1, 2, 4, and 5, regression results similar to those in Table 6 separately for each sub-sample. In columns 3 and 6 , we interact liquidation and the indicator for above-median market thickness and run the regression on the full sample to determine if liquidation's impact is significantly different in thick markets. For these interacted regressions, in the first stage we interact the instrument share converted and the above median indicator to generate two instruments for the two endogenous variables. Further, all control variables and fixed effects are interacted with above-median market thickness. Panel A focuses on the two dependent variables that have to do with plant continuation: continues and holding time. Panel B displays the results with regards to two measures of utilization: occupied and ln(average employment). All dependent variables are measured 5 years after bankruptcy and are defined as in Table 6. All regressions are estimated by 2SLS and contain the full set of control variables in Column 3 of Table 3, including division-by-year and industry fixed effects. Standard errors, clustered at the division-by-year level, are shown in parentheses. *, **, and *** denote statistical significance at the $10 \%, 5 \%$, and $1 \%$ level, respectively.

\section{Panel A: Plant continuation}

\begin{tabular}{|c|c|c|c|c|c|c|}
\hline \multirow{2}{*}{$\begin{array}{l}\text { Dependent variable: } \\
\text { Above or below median: }\end{array}$} & \multicolumn{3}{|c|}{ Continues } & \multicolumn{3}{|c|}{ Holding Time } \\
\hline & $\begin{array}{l}\text { Above } \\
(1)\end{array}$ & $\begin{array}{l}\text { Below } \\
(2)\end{array}$ & $\begin{array}{l}\text { Interacted } \\
(3)\end{array}$ & $\begin{array}{l}\text { Above } \\
(4)\end{array}$ & $\begin{array}{l}\text { Below } \\
(5)\end{array}$ & $\begin{array}{l}\text { Interacted } \\
(6)\end{array}$ \\
\hline $\begin{array}{l}\text { Liquidation } \\
\text { Liquidation * above median }\end{array}$ & $\begin{array}{l}-0.337^{* * *} \\
(0.101)\end{array}$ & $\begin{array}{l}-0.321^{* * *} \\
(0.076)\end{array}$ & $\begin{array}{l}-0.321^{* * *} \\
(0.076) \\
-0.016 \\
(0.127)\end{array}$ & $\begin{array}{l}-1.449^{* * *} \\
(0.492)\end{array}$ & $\begin{array}{l}-1.836^{* * *} \\
(0.360)\end{array}$ & $\begin{array}{l}-1.836^{* * *} \\
(0.360) \\
0.387 \\
(0.609)\end{array}$ \\
\hline $\begin{array}{l}\text { Control Variables } \\
\text { Div x Year FE } \\
\text { Observations }\end{array}$ & $\begin{array}{l}\text { Yes } \\
\text { Yes } \\
64,000\end{array}$ & $\begin{array}{l}\text { Yes } \\
\text { Yes } \\
65,000\end{array}$ & $\begin{array}{l}\text { Yes } \\
\text { Yes } \\
129,000\end{array}$ & $\begin{array}{l}\text { Yes } \\
\text { Yes } \\
64,000\end{array}$ & $\begin{array}{l}\text { Yes } \\
\text { Yes } \\
65,000\end{array}$ & $\begin{array}{l}\text { Yes } \\
\text { Yes } \\
129,000\end{array}$ \\
\hline \multicolumn{7}{|c|}{ Panel B: Utilization } \\
\hline $\begin{array}{l}\text { Dependent variable: } \\
\text { Above or below median: }\end{array}$ & $\begin{array}{l}\text { Above } \\
(1)\end{array}$ & $\begin{array}{l}\text { Occupied } \\
\text { Below } \\
(2)\end{array}$ & $\begin{array}{l}\text { Interacted } \\
(3)\end{array}$ & $\begin{array}{l}\quad \operatorname{Ln}( \\
\text { Above } \\
(4)\end{array}$ & $\begin{array}{l}\text { Avg. Emplo, } \\
\text { Below } \\
(5)\end{array}$ & $\begin{array}{l}\text { ment) } \\
\text { Interacted } \\
(6)\end{array}$ \\
\hline $\begin{array}{l}\text { Liquidation } \\
\text { Liquidation * above median }\end{array}$ & $\begin{array}{l}0.080 \\
(0.129)\end{array}$ & $\begin{array}{l}-0.324^{* * *} \\
(0.109)\end{array}$ & $\begin{array}{l}-0.324^{* * *} \\
(0.109) \\
0.404^{* *} \\
(0.169)\end{array}$ & $\begin{array}{l}0.190 \\
(0.413)\end{array}$ & $\begin{array}{l}-0.790^{* * *} \\
(0.278)\end{array}$ & $\begin{array}{l}-0.790^{* * *} \\
(0.278) \\
0.980^{* *} \\
(0.498)\end{array}$ \\
\hline $\begin{array}{l}\text { Control Variables } \\
\text { Div x Year FE } \\
\text { Observations }\end{array}$ & $\begin{array}{l}\text { Yes } \\
\text { Yes } \\
64,000\end{array}$ & $\begin{array}{l}\text { Yes } \\
\text { Yes } \\
65,000\end{array}$ & $\begin{array}{l}\text { Yes } \\
\text { Yes } \\
129,000\end{array}$ & $\begin{array}{l}\text { Yes } \\
\text { Yes } \\
64,000\end{array}$ & $\begin{array}{l}\text { Yes } \\
\text { Yes } \\
65,000\end{array}$ & $\begin{array}{l}\text { Yes } \\
\text { Yes } \\
129,000\end{array}$ \\
\hline
\end{tabular}




\section{Table 8}

Heterogeneous Effects on Utilization - Access to Capital

This table shows how the effects of liquidation vary depending on the access to small business finance in the local market. Counties with an above-median share of bank loans going to small firms (firms with less than $\$ 1$ million in annual revenue) are defined as having high access to capital, while below-median counties have low access to capital. We then present, in columns 1, 2, 4, and 5, regression results similar to those in Table 6 separately for plants in above- and below-median counties. In columns 3 and 6 , we interact liquidation and the indicator for above-median access to capital and run the regression on the full sample to determine if liquidation's impact is significantly different in markets with high access to capital. For these interacted regressions, in the first stage we interact the instrument share converted and the above median indicator to generate two instruments for the two endogenous variables. Further, all control variables and fixed effects are interacted with above-median access to capital. Panel A focuses on the two dependent variables that have to do with plant continuation: continues and holding time. Panel B displays the results with regards to two measures of utilization: occupied and ln(average employment). All dependent variables are measured 5 years after bankruptcy and are defined as in Table 6. All regressions are estimated by 2SLS and contain the full set of control variables in Column 3 of Table 3, including division-by-year and industry fixed effects. Standard errors, clustered at the division-by-year level, are shown in parentheses. *, **, and *** denote statistical significance at the $10 \%, 5 \%$, and $1 \%$ level, respectively.

\section{Panel A: Plant continuation}

\begin{tabular}{|c|c|c|c|c|c|c|}
\hline \multirow{2}{*}{$\begin{array}{l}\text { Dependent variable: } \\
\text { Above or below median: }\end{array}$} & \multicolumn{3}{|c|}{ Continues } & \multicolumn{3}{|c|}{ Holding Time } \\
\hline & $\begin{array}{l}\text { Above } \\
(1)\end{array}$ & $\begin{array}{l}\text { Below } \\
(2)\end{array}$ & $\begin{array}{l}\text { Interacted } \\
(3)\end{array}$ & $\begin{array}{l}\text { Above } \\
(5)\end{array}$ & $\begin{array}{l}\text { Below } \\
(6)\end{array}$ & $\begin{array}{l}\text { Interacted } \\
(6)\end{array}$ \\
\hline $\begin{array}{l}\text { Liquidation } \\
\text { Liquidation * above median }\end{array}$ & $\begin{array}{l}-0.273^{* * *} \\
(0.083)\end{array}$ & $\begin{array}{l}-0.341^{* * *} \\
(0.126)\end{array}$ & $\begin{array}{l}-0.341^{* * *} \\
(0.126) \\
0.069 \\
(0.151)\end{array}$ & $\begin{array}{l}-1.402^{* * *} \\
(0.413)\end{array}$ & $\begin{array}{l}-1.999^{* * *} \\
(0.569)\end{array}$ & $\begin{array}{l}-1.999 * * * \\
(0.569) \\
0.596 \\
(0.703)\end{array}$ \\
\hline Control Variables & Yes & Yes & Yes & Yes & Yes & Yes \\
\hline Div x Year FE & Yes & Yes & Yes & Yes & Yes & Yes \\
\hline Observations & 50,000 & 49,000 & 99,000 & 50,000 & 49,000 & 99,000 \\
\hline
\end{tabular}

Panel B: Utilization

\begin{tabular}{lllllll}
\hline Dependent variable: & \multicolumn{3}{c}{ Occupied } & \multicolumn{3}{c}{ Ln(Avg. Employment) } \\
Above or below median: & Above & Below & Interacted & Above & Below & Interacted \\
& $(3)$ & $(4)$ & $(3)$ & $(5)$ & $(6)$ & $(3)$ \\
\hline Liquidation & -0.018 & $-0.450^{* *}$ & $-0.450^{* *}$ & -0.206 & $-1.197^{* *}$ & $-1.200^{* *}$ \\
& $(0.111)$ & $(0.193)$ & $(0.193)$ & $(0.310)$ & $(0.480)$ & $(0.480)$ \\
Liquidation * above median & & & $0.432^{*}$ & & & $0.992^{*}$ \\
& & & $(0.223)$ & & & $(0.571)$ \\
\hline Control Variables & Yes & Yes & Yes & Yes & Yes & Yes \\
Div x Year FE & Yes & Yes & Yes & Yes & Yes & Yes \\
Observations & 50,000 & 49,000 & 99,000 & 50,000 & 49,000 & 99,000 \\
\hline
\end{tabular}




\section{Table 9}

Controlling for benchmark utilization

This table shows that liquidation affects plant utilization even when controlling for local utilization rates. Benchmark utilization rates come from a $5 \%$ random sample of establishments in the same county as each bankrupt plant, with utilization measured 5 years after bankruptcy in an identical manner to the bankrupt plant. Panel A focuses on liquidation's impact on establishment occupancy, similar to column 6 of Table 6, with the dependent variable being the occupied dummy for the bankrupt plant. High occupancy county is a dummy indicating that a bankrupt plant is in a county with above-median benchmark occupancy, and liquidation*high occupancy is the interaction of this dummy with the liquidation indicator. Liquidation*thick market and liquidation*high access to capital are interactions between the liquidation indicator and local market conditions, as in Tables 7 and 8. For all interaction terms we also include the interaction between the instrument and that variable in the first stage regression. Panel B is similar to Panel A, but instead showing the effect on $\ln$ (avg. employment). All regressions are estimated by 2SLS and contain the full set of control variables in Column 3 of Table 3, including division-by-year and industry fixed effects. Standard errors, clustered at the division-by-year level, are shown in parentheses. ${ }^{*},{ }^{* *}$, and ${ }^{* * *}$ denote statistical significance at the $10 \%, 5 \%$, and $1 \%$ level, respectively.

Panel A: Occupied

\begin{tabular}{|c|c|c|c|c|c|}
\hline Dependent variable: & \multicolumn{5}{|c|}{ Occupied } \\
\hline Liquidation & $\begin{array}{l}-0.173^{* *} \\
(0.079)\end{array}$ & $\begin{array}{l}-0.321^{* * *} \\
(0.109)\end{array}$ & $\begin{array}{l}-0.295^{* *} \\
(0.118)\end{array}$ & $\begin{array}{l}-0.448^{* *} \\
(0.193)\end{array}$ & $\begin{array}{l}-0.445^{* *} \\
(0.196)\end{array}$ \\
\hline High occupancy county & $\begin{array}{l}0.045^{* * *} \\
(0.008)\end{array}$ & $\begin{array}{l}0.057^{* * * *} \\
(0.010)\end{array}$ & $\begin{array}{l}0.074^{* * *} \\
(0.026)\end{array}$ & $\begin{array}{l}0.044 * * * \\
(0.013)\end{array}$ & $\begin{array}{l}0.047 \\
(0.031)\end{array}$ \\
\hline Liquidation $*$ Thick Market & & $\begin{array}{l}0.399^{* *} \\
(0.169)\end{array}$ & $\begin{array}{l}0.402^{* *} \\
(0.169)\end{array}$ & & \\
\hline Liquiation * High Access to Capital & & & & $\begin{array}{l}0.433^{*} \\
(0.223)\end{array}$ & $\begin{array}{l}0.433^{*} \\
(0.223)\end{array}$ \\
\hline Liquidation $*$ High Occupancy & & & $\begin{array}{l}-0.044 \\
(0.062)\end{array}$ & & $\begin{array}{l}-0.006 \\
(0.069)\end{array}$ \\
\hline Control Variables & Yes & Yes & Yes & Yes & Yes \\
\hline Div x Year FE & Yes & Yes & Yes & Yes & Yes \\
\hline Observations & 129,000 & 129,000 & 129,000 & 99,000 & 99,000 \\
\hline \multicolumn{6}{|c|}{ Panel B: Ln(Avg. Employment) } \\
\hline Dependent variable: & & $\operatorname{Ln}(\mathrm{Av}$ & g. Employı & ent) & \\
\hline & $(1)$ & $(2)$ & $(3)$ & $(4)$ & $(5)$ \\
\hline Liquidation & $\begin{array}{l}-0.408^{*} \\
(0.217)\end{array}$ & $\begin{array}{l}-0.786^{* * *} \\
(0.279)\end{array}$ & $\begin{array}{l}-0.733^{* *} \\
(0.306)\end{array}$ & $\begin{array}{l}-1.193^{* *} \\
(0.481)\end{array}$ & $\begin{array}{l}-1.116^{* *} \\
(0.494)\end{array}$ \\
\hline High occupancy county & $\begin{array}{l}0.088^{* * *} \\
(0.020)\end{array}$ & $\begin{array}{l}0.100^{* * *} \\
(0.026)\end{array}$ & $\begin{array}{l}0.135^{*} \\
(0.072)\end{array}$ & $\begin{array}{l}0.079^{* *} \\
(0.036)\end{array}$ & $\begin{array}{l}0.133 \\
(0.089)\end{array}$ \\
\hline Liquidation $*$ Thick Market & & $\begin{array}{l}0.971^{*} \\
(0.498)\end{array}$ & $\begin{array}{l}0.977^{* *} \\
(0.497)\end{array}$ & & \\
\hline Liquiation * High Access to Capital & & & & $\begin{array}{l}0.992^{*} \\
(0.572)\end{array}$ & $\begin{array}{l}0.994^{*} \\
(0.572)\end{array}$ \\
\hline Liquidation * High Occupancy & & & $\begin{array}{l}-0.089 \\
(0.165)\end{array}$ & & $\begin{array}{l}-0.131 \\
(0.193)\end{array}$ \\
\hline Control Variables & Yes & Yes & Yes & Yes & Yes \\
\hline Div x Year FE & Yes & Yes & Yes & Yes & Yes \\
\hline Observations & 129,000 & 129,000 & 129,000 & 99,000 & 99,000 \\
\hline
\end{tabular}

